\title{
Strategies for the Synthesis of 19-nor-Vitamin D Analogs
}

\author{
Susana Fernández * and Miguel Ferrero *
}

Departamento de Química Orgánica e Inorgánica, Universidad de Oviedo, 33006 Oviedo, Asturias, Spain

* Correspondence: fernandezgsusana@uniovi.es (S.F.); mferrero@uniovi.es (M.F.); Tel.: +34-985-102-984 (S.F.); +34-985-105-013 (M.F.)

Received: 18 June 2020; Accepted: 21 July 2020; Published: 22 July 2020

\begin{abstract}
Dihydroxyvitamin $\mathrm{D}_{3}\left[1 \alpha, 25-(\mathrm{OH})_{2}-\mathrm{D}_{3}\right]$, the hormonally active form of vitamin $\mathrm{D}_{3}$, classically regulates bone formation, calcium, and phosphate homeostasis. In addition, this hormone also exerts non-classical effects in a wide variety of target tissues and cell types, such as inhibition of the proliferation and stimulation of the differentiation of normal and malignant cells. However, to produce these actions, supraphysiological doses are required resulting in calcemic effects that limit the use of this natural hormone. During the past 30 years, many structurally modified analogs of the $1 \alpha, 25-(\mathrm{OH})_{2}-\mathrm{D}_{3}$ have been synthesized in order to find derivatives that can dissociate the beneficial antiproliferative effects from undesired calcemic effects. Among these candidates, $1 \alpha, 25-(\mathrm{OH})_{2}-19-n o r-\mathrm{D}_{3}$ analogs have shown promise as good derivatives since they show equal or better activity relative to the parent hormone but with reduced calcemic effects. In this review, we describe the synthetic strategies to obtain the 19-nor- $\mathrm{D}_{3}$ derivatives and briefly describe their physiological activities.
\end{abstract}

Keywords: vitamin D; 19-nor-vitamin $\mathrm{D}_{3}$; 19-nor-vitamin $\mathrm{D}_{2}$; synthesis; modified analogs

\section{Introduction}

The steroid hormone $1 \alpha, 25$-dihydroxyvitamin $\mathrm{D}_{3}\left[1 \alpha, 25-(\mathrm{OH})_{2}-\mathrm{D}_{3}\right](2$, Figure 1$)$ is the active form of vitamin $\mathrm{D}_{3}(\mathbf{1})$, which can be synthesized in the skin or obtained from dietary sources [1]. Its primary physiological role is in the regulation of bone formation, calcium, and phosphate homeostasis [2]. In addition, it is a potent differentiator and growth inhibitor of several types of cancer cells. These observations have suggested its potential therapeutic application, but supraphysiological doses are required, resulting in calcemic effects that limit the use of this natural hormone [3,4].
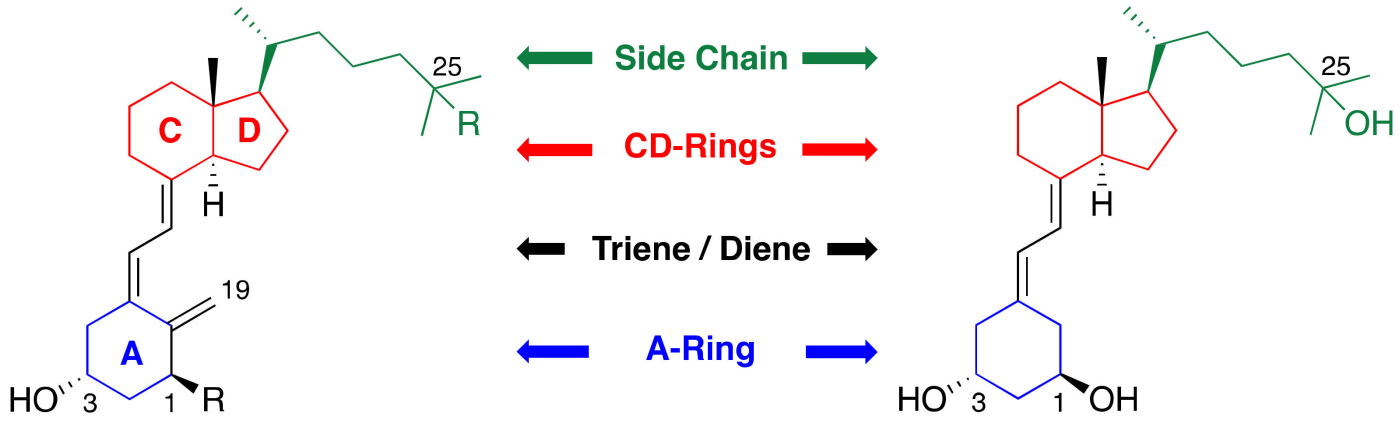

1, R= H; Vitamin $D_{3}$

3, $1 \alpha, 25-(\mathrm{OH})_{2}-19-n o r-\mathrm{D}_{3}$

2, $\mathrm{R}=\mathrm{OH} ; 1 \alpha, 25-(\mathrm{OH})_{2}-\mathrm{D}_{3}$

Figure 1. Structures of vitamin $\mathrm{D}_{3}$, its hormonally active form $1 \alpha, 25-(\mathrm{OH})_{2}-\mathrm{D}_{3}$, and the $1 \alpha, 25-(\mathrm{OH})_{2}-$ 19-nor- $\mathrm{D}_{3}$ analog. 
In order to overcome this limitation, many structurally modified analogs of $1 \alpha, 25-(\mathrm{OH})_{2}-\mathrm{D}_{3}$ have been synthesized in the past three decades [5-11]. Among these modifications, the removal of carbon C19 on the A-ring results in selective activities, inducing potent differentiation and growth inhibition of tumor cells, without a parallel increase in bone calciotropic activity. As a consequence of this structural characteristic, these analogs are more stable since they cannot undergo a [1,7] hydrogen sigmatropic shift to transform into their respective previtamin forms. The objective of this review is to collect the synthetic strategies that have been employed to obtain $1 \alpha, 25-(\mathrm{OH})_{2}-19-$ nor- $\mathrm{D}_{3}(3)$ derivatives.

The structurally dynamic hormone 2 presents four parts: An A-ring, conjugated triene (seco B-ring), CD-ring, and side chain. The main characteristic of 19-nor analogs is the absence of the C19 methylene group, so the "triene" part of these analogs is altered to just a diene moiety.

A summary of the major synthetic routes utilized to prepare $1 \alpha, 25-(\mathrm{OH})_{2}-19$-nor-vitamin $\mathrm{D}_{3}$ analogs is depicted in Figure 2. Method I is related to the direct modifications in the seco-B steroid precursors of type A. It is a linear approach to synthesizing new 19-nor-vitamin D analogs via a cyclovitamin intermediate $\mathbf{B}$. The main characteristic of the synthesis, its linearity, is a great disadvantage since only in a few modifications can be used, and the global yields are lower than that obtained when convergent strategies are utilized. Method II constructs the diene moiety of 19-nor-vitamin D using the approach developed by Lythgoe [12] through a Wittig-Horner coupling reaction of a phosphine oxide A-ring synthon precursor $\mathbf{D}$ with a CD-ring/side chain fragment $\mathbf{C}$, generally obtained from the oxidation of easily available vitamin $\mathrm{D}_{2}$ or vitamin $\mathrm{D}_{3}(\mathbf{A})$. It is the most used method to produce any kind of vitamin $\mathrm{D}$ analogs due to the versatility provided by using convergent synthesis. The limitation of this route, the tedious synthesis of the A-ring fragment $\mathbf{D}$, has been circumvented by the development of several pathways to synthesize the appropriate A-ring precursors from natural starting materials. Another convergent approach to synthesizing 19-nor derivatives is through Julia olefination (Method III), which consists of the addition of a CD-ring/side chain sulfonyl-stabilized carbanion of $\mathbf{E}$ to an A-ring ketone $\mathbf{F}$, followed by elimination to form an alkene. It has also been applied to the reverse synthon precursors, that is, the sulfone of the A-ring $\mathbf{G}$ and a vinyl halide of the CD-ring/side chain $\mathbf{H}$ (Method IV). To construct the diene part of the molecule, approaches based on the Suzuki-Miyaura reaction between the CD-ring boronate ester $\mathbf{I}$ and vinyl halides of the corresponding A-ring fragment $\mathbf{J}$ have been used (Method V). Method VI, based on the initial studies of Mazur, involves a bicyclo[3.1.0]hexane intermediate $\mathbf{K}$, which is coupled with the CD ring/side chain fragment $\mathbf{C}$. Solvolysis of an intermediate similar to $\mathbf{B}$ gives rise to vitamin D metabolites and analogs.

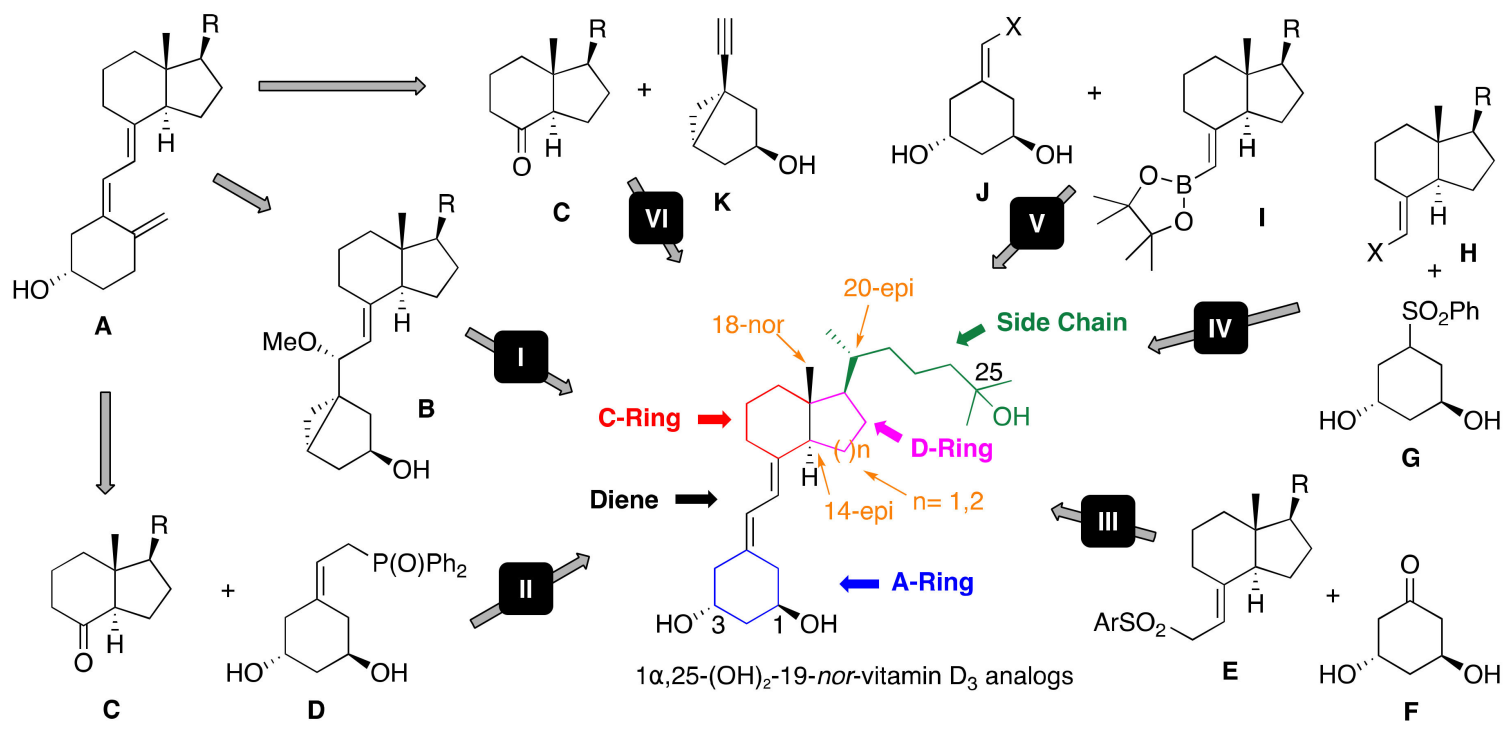

Figure 2. Major synthetic routes to prepare $1 \alpha, 25-(\mathrm{OH})_{2}-19-$ nor-vitamin $\mathrm{D}_{3}$ analogs. 
The information presented in this article is structured as follows. First, the syntheses of 19-nor vitamin $\mathrm{D}\left(\mathrm{D}_{2} / \mathrm{D}_{3}\right)$ with no other modifications in their structure compared to vitamin $\mathrm{D}$, except for the absence of the methyl group at C19, are described. Then, different methods are shown for the syntheses of analogs with modifications in the A ring, followed by those in the diene part, the CD-ring, and, finally, the side chain. For cases of analogs with more than one modification, the methods are classified as one of the four categories indicated above and then subclassified by the additional modification(s) following the same order.

\section{Synthesis of $1 \alpha, 25-(\mathrm{OH})_{2}$-19-nor-Vitamin D}

There are several synthetic approaches to synthesizing $1 \alpha, 25-(\mathrm{OH})_{2}-19-n o r-\mathrm{D}_{3}$. Thus, DeLuca and co-workers [13] described the synthesis of 3a via oxidative degradation of the $1 \alpha$-hydroxycyclovitamin intermediate 9 (Scheme 1). The first step consists of the transformation of 25-hydroxyvitamin $\mathrm{D}_{3}$ (4a) into $1 \alpha$-acetoxy-25-OH-3,5-cyclovitamin $\mathrm{D}_{3}(5)$. Compound 5 was oxidized to form a mixture of diols 6, which was subjected to diol cleavage to obtain the 10-oxo derivative 7 . The latter was reduced to produce an epimeric mixture of alcohols 8 . The mixture was then mesylated and reduced to generate $1 \alpha, 25-(\mathrm{OH})_{2}-19-$ nor-cyclo- $\mathrm{D}_{3}$ 9, which underwent cycloreversion with acetic acid to 10 and 11. Final hydrolysis of the acetates $\mathbf{1 0}$ and $\mathbf{1 1}$ resulted in the final product $1 \alpha, 25-(\mathrm{OH})_{2}-19-$ nor- $\mathrm{D}_{3}(3 \mathbf{a})$. This procedure allowed the authors to prepare $3 \mathbf{a}$ for the first time, which showed a combination of high potency induction of differentiation and very low bone calcification activity.

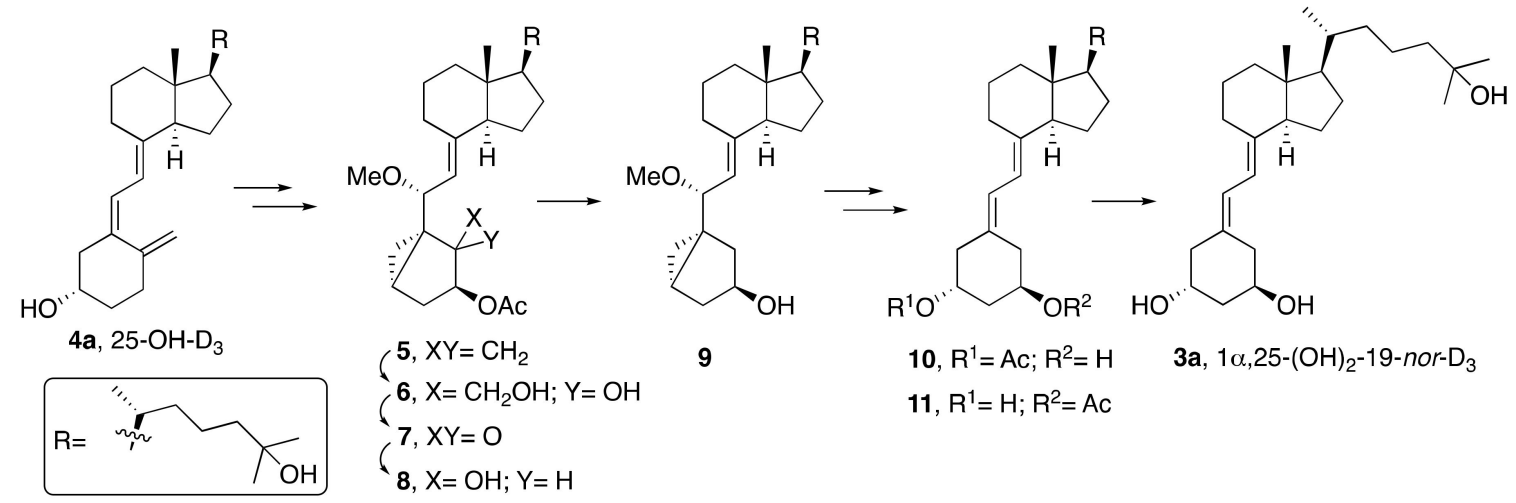

Scheme 1. The first synthesis of $1 \alpha, 25-(\mathrm{OH})_{2}-19-$ nor-vitamin $\mathrm{D}_{3}$.

On the other hand, Nagasawa and coworkers [14] reported the preparation of $1 \alpha, 25-(\mathrm{OH})_{2}-19-n o r-\mathrm{D}$ (3a) and (3b) from 25-OH-D (4a and $4 \mathbf{b}$ ) (Scheme 2). Compounds $4 \mathbf{a}$ and $\mathbf{4 b}$ were obtained through a bioconversion method. The key intermediate is 10-keto-3,5-cyclovitamin D 14 formed in a similar manner to that previously described. Conversion of $\mathbf{1 4} \mathbf{a}-\mathbf{b}$ to $\mathbf{3} \mathbf{a}-\mathbf{b}$ was carried out using a regio- and stereoselective hydroboration reaction with the olefin 16 with the bulky reagent 9-BBN, affording the $1 \alpha$-hydroxy-3,5-cyclovitamin D derivatives 17 exclusively. Cycloreversion of 17 with acetic acid followed by hydrolysis of the resulting acetate produced a diol, which was deprotected at C25 with CSA to produce $1 \alpha, 25-(\mathrm{OH})_{2}-19-n o r-\mathrm{D}_{3}(3 \mathbf{a})$ and $-\mathrm{D}_{2}(3 \mathbf{b})$, respectively. Paricalcitol (3b) was approved in the late 1990s for the treatment and prevention of secondary hyperparathyroidism associated with chronic renal failure. 


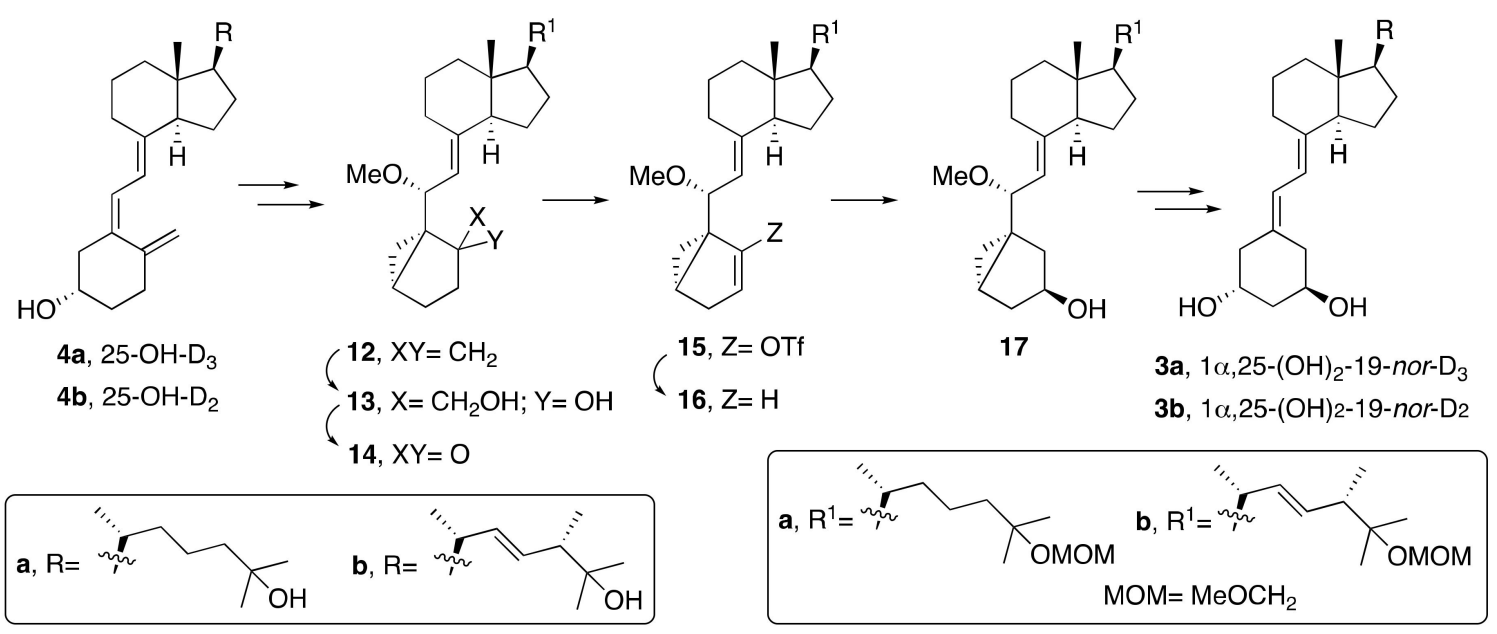

Scheme 2. Routes to $1 \alpha, 25-(\mathrm{OH})_{2}-19$-nor-vitamin D using regio- and stereoselective hydroboration.

An alternative synthesis involving a new 19-nor A-ring precursor 20 (Scheme 3) and based on the well-known sigmatropic rearrangement of cyclopropylic alcohols into homoallylic alcohols was reported by Vandewalle and co-workers [15]. They proposed two alternative routes to the A-ring precursor 20. The first chemical approach began with (-)-quinic acid (18) and centered on the removal of the $\mathrm{C} 1$ and $\mathrm{C} 4$ hydroxyl groups and on intramolecular alkylation of an ester-enolate to generate the bicyclic product precursor of 20. Then, the ester was transformed into an aldehyde that was finally converted into an alkyne using dimethyl diazomethylphosphonate. They also developed a chemoenzymatic route to the A-ring 20 starting from cis-1,3,5-cyclohexanetriol (19), easily available upon catalytic hydrogenation of phloroglucinol. In order to obtain the vitamin D analog, the lithiated alkyne $\mathbf{2 0}$ was reacted with a ketone $\mathbf{2 1}$ to generate the propargylic alcohol, which was subsequently reduced to the $(E)$-allylic alcohol 22. Acid-catalyzed solvolysis of 22 produced $1 \alpha, 25-(\mathrm{OH})_{2}-19-n o r-\mathrm{D}_{3}$ (3a). The $E$-geometry of the 7,8-double bond arises from the steric hindrance exerted by the D-ring. Thus, because of the $\mathrm{C}_{2}$-symmetry nature of the A-ring, only the desired geometry of $3 \mathbf{a}$ was observed.

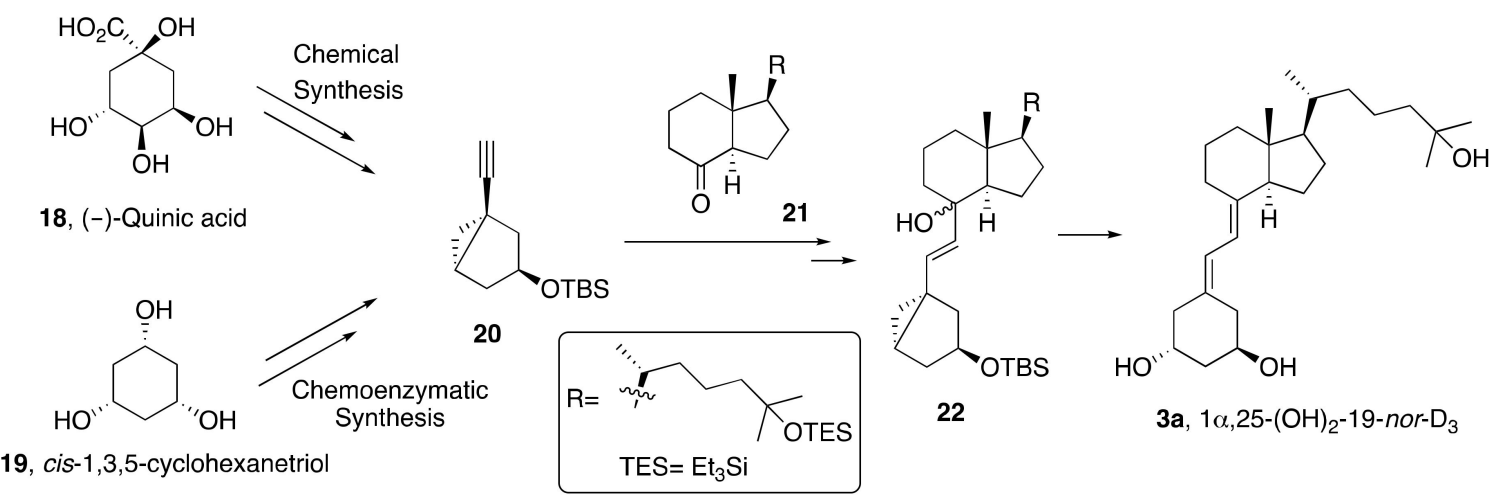

Scheme 3. Convergent routes to $1 \alpha, 25-(\mathrm{OH})_{2}-19$-nor-vitamin $\mathrm{D}_{3}$.

DeLuca's research group [16] described an alternative approach to preparing $1 \alpha, 25-(\mathrm{OH})_{2^{-}}$ 19-nor $-\mathrm{D}_{3}(\mathbf{3 a})$ that consists of a convergent route more suitable for large-scale preparations (Scheme 4). The new synthesis entails the independent preparation of a phosphine oxide A-ring precursor 23 and the CD-ring/side chain ketone $\mathbf{2 4}$ and their eventual condensation through a Wittig-Horner reaction to obtain the 19-nor-vitamin D derivative 25, which, after deprotection, yielded the desired compound 3a. They chose (-)-quinic acid (18) as the starting material since it features the correct hydroxy stereochemistry and is commercially available. 


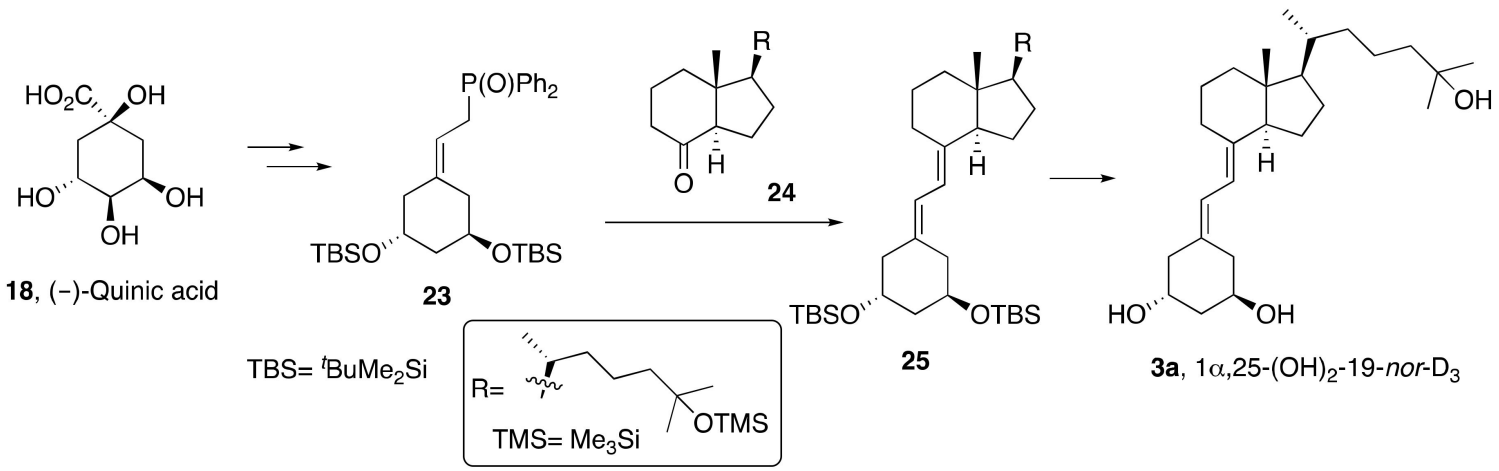

Scheme 4. Large-scale preparation of $1 \alpha, 25-(\mathrm{OH})_{2}-19-$ nor-vitamin $\mathrm{D}_{3}$.

Nagasawa's group described [17] a new synthetic method to obtain A-ring synthons $\mathbf{2 8}$ (Scheme 5) based on ring-closing metathesis from a linear precursor, and then they applied it to synthesize $1 \alpha, 25-(\mathrm{OH})_{2}-19-n o r-\mathrm{D}_{3}(3 a)$. This strategy enabled the preparation of an A-ring with a more flexible substitution pattern. For the synthesis of A-ring precursors 28 they chose cyclohexene 27 as an intermediate, which was obtained from the corresponding chiral epoxide alcohol 26, derived from 1,3-propanediol. These A-rings 28 were used to carry out the coupling with the appropriate functionalized CD-ring/side chain fragment 29 to produce $1 \alpha, 25-(\mathrm{OH})_{2}-19-$ nor $-\mathrm{D}_{3}(3 \mathbf{a})$.

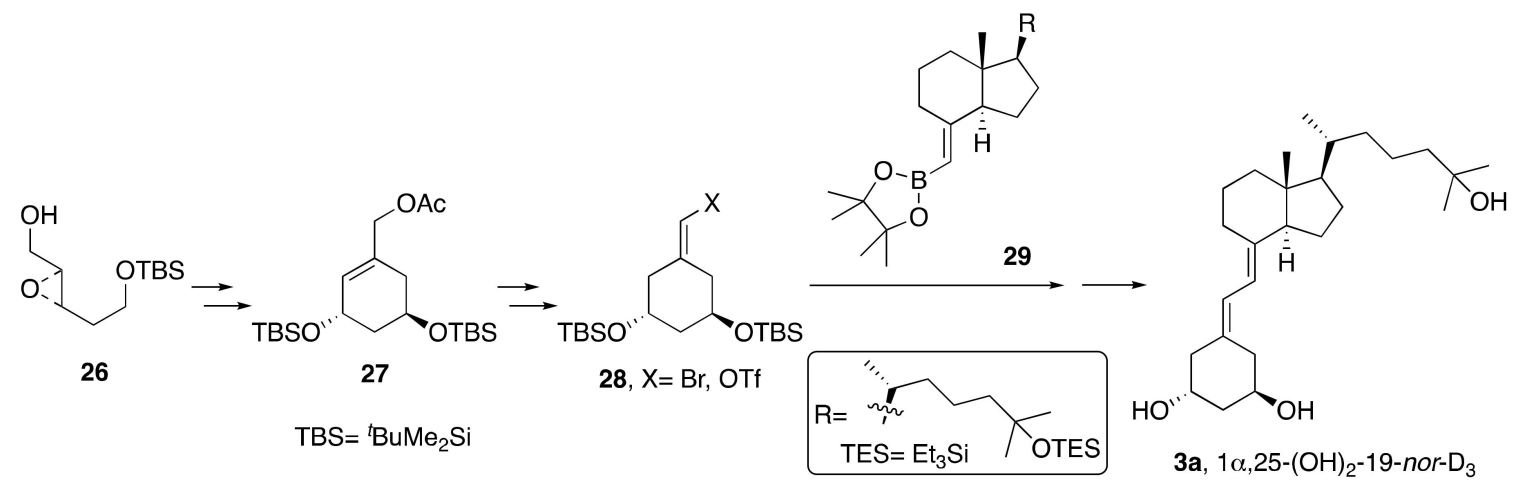

Scheme 5. Use of ring-closing metathesis to synthesize $1 \alpha, 25-(\mathrm{OH})_{2}-19-$ nor-vitamin $\mathrm{D}_{3}$.

\section{Synthesis of A-Ring-Modified 1 1 $2,25-(\mathrm{OH})_{2}-19-n o r-V i t a m i n ~ D$}

DeLuca and co-workers [18] reported the synthesis of $1 \alpha, 2 \alpha / \beta, 25-(\mathrm{OH})_{3}-19-n o r-\mathrm{D}_{3}$ and their alkoxy derivatives (31, Scheme 6). The objective was to synthesize new analogs with potential applications as drugs for osteoporosis but with no calcemic effects. They were prepared through a convergent route, starting from (-)-quinic acid (18) and 25-hydroxy-protected Grundmann's ketone (21) followed by the Wittig-Horner coupling approach using the phosphine oxide precursors 30. Since an alkylation of the 2-hydroxy group was performed at the end of the synthesis, several analogs with different alkoxy substituents at the 2-position were conveniently obtained. On the basis of the same synthetic approach, Shimizu, Yamada, and co-workers [19] synthesized C2-alkoxy-substituted analogs 31 by a new sequence starting from D-glucose (32) as a chiral template to prepare A-ring synthons $\mathbf{3 0 .}$ Transformation of the pyranoside ring into the A-ring carbocycle was achieved by the Pd-catalyzed Ferrier rearrangement. Using this new methodology, analogs 31 were obtained in a novel cost-effective method by coupling of the A-ring precursors 30 with the CD-ring/side chain moiety 33 . 
<smiles>O=C(O)[C@@]1(O)CC(O)C(O)[C@H](O)C1</smiles>

18, (-)-Quinic acid<smiles>OCC1O[C@H](O)[C@@H](O)C(O)[C@H]1O</smiles>

32, D-Glucose

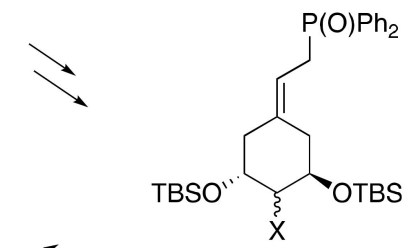

$$
\begin{aligned}
& 30, \mathrm{C} 2-\alpha \text { or } \mathrm{C} 2-\beta \\
& \mathrm{X}=\mathrm{OTMS}, \mathrm{O}\left(\mathrm{CH}_{2}\right)_{3} \mathrm{OTBS}, \mathrm{OBn} \text {, } \\
& \mathrm{O}\left(\mathrm{CH}_{2}\right)_{2} \mathrm{OTBS}, \mathrm{CH}_{2} \mathrm{CONEt}_{2}
\end{aligned}
$$

$\mathrm{TBS}={ }^{\mathrm{t}} \mathrm{BuMe}_{2} \mathrm{Si}$

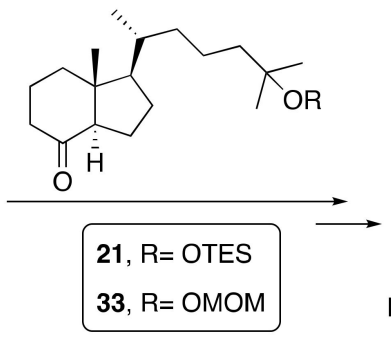

$\mathrm{TES}=\mathrm{Et}_{3} \mathrm{Si}$

$\mathrm{MOM}=\mathrm{MeOCH}_{2}$

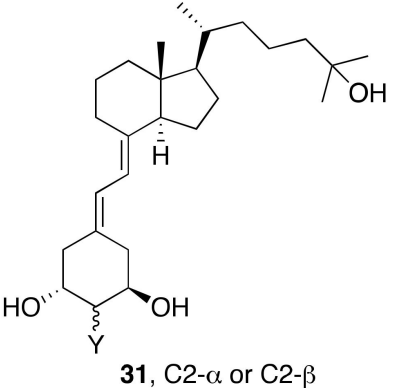

$\mathrm{Y}=\mathrm{OH}, \mathrm{O}\left(\mathrm{CH}_{2}\right)_{3} \mathrm{OH}, \mathrm{OBn}$ $\mathrm{O}\left(\mathrm{CH}_{2}\right)_{2} \mathrm{OH}, \mathrm{CH}_{2} \mathrm{CONEt}_{2}$

Scheme 6. Preparation of C2-substituted $1 \alpha, 25-(\mathrm{OH})_{2}-19-$-nor-vitamin $\mathrm{D}_{3}$.

The results of previous studies on 19-nor analogs of the hormone $1 \alpha, 25-(\mathrm{OH})_{2}-\mathrm{D}_{3}(2)$ indicate that substituents on $\mathrm{C} 2$ completely change the biological potency of these derivatives since they alter the orientation of the $1 \alpha$-hydroxyl group. Thus, DeLuca's group reported new highly active isomers 36 (Scheme 7) via methylene [20] or ethylene (both $E$ and $Z$ geometrical isomers) [21] intermediates 35, prepared in a convergent manner from (-)-quinic acid. The synthetic pathway involved a Wittig-Horner coupling of the corresponding A-ring phosphine oxides 34 with the corresponding 25-hydroxy protected Grundmann's ketone 21. Notably, the analogs 35 possessed C2-substituents as $E$ - and Z-isomers of 3 '-hydroxypropylidene, and a derivative of the former compound possessed a $3^{\prime}$-(methoxymethyl)propylidene [22]. In vivo tests revealed that the calcemic activity of all analogs in the $(E)$-series was considerably higher than that of the native hormone.

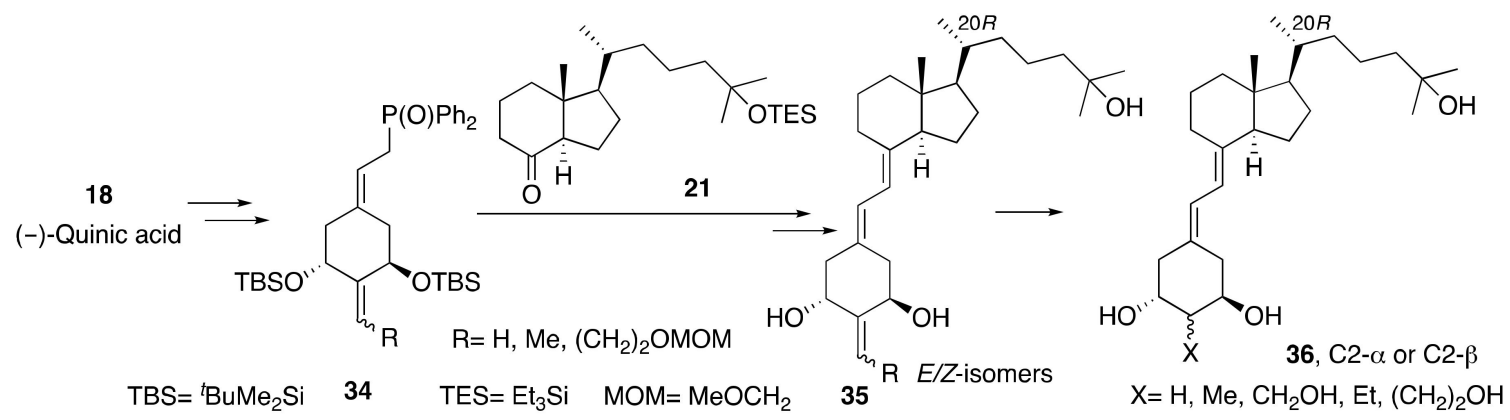

Scheme 7. Preparation of C2-substituted $1 \alpha, 25-(\mathrm{OH})_{2}-19$-nor-vitamin $\mathrm{D}_{3}$ from quinic acid.

Novel C2-substituted analogs of $1 \alpha, 25-(\mathrm{OH})_{2}$-19-nor-vitamin $\mathrm{D}_{3}$ were efficiently synthesized by Kittaka and co-workers [23,24]. The C2-alkyl A-ring precursors were prepared as $(3 R, 5 R)-4$-alkyl-3,5dihydroxycyclohexanones 37 (Scheme 8 ) from (-)-quinic acid through radical allylation at the $\mathrm{C} 4$ position of methyl (-)-quinate. A new type of the CD-ring coupling partner 38 with an elongated two-carbon unit was synthesized from 25-hydroxy Grundmann's ketone. To construct a diene unit between the A-ring and the CD-ring, modified Julia olefination was used. The analog 39c [C2 $\alpha$-(3-hydroxypropyl) derivative] showed an increase in both the vitamin D receptor (VDR) binding affinity and potency in the induction of HL-60 cell differentiation. 


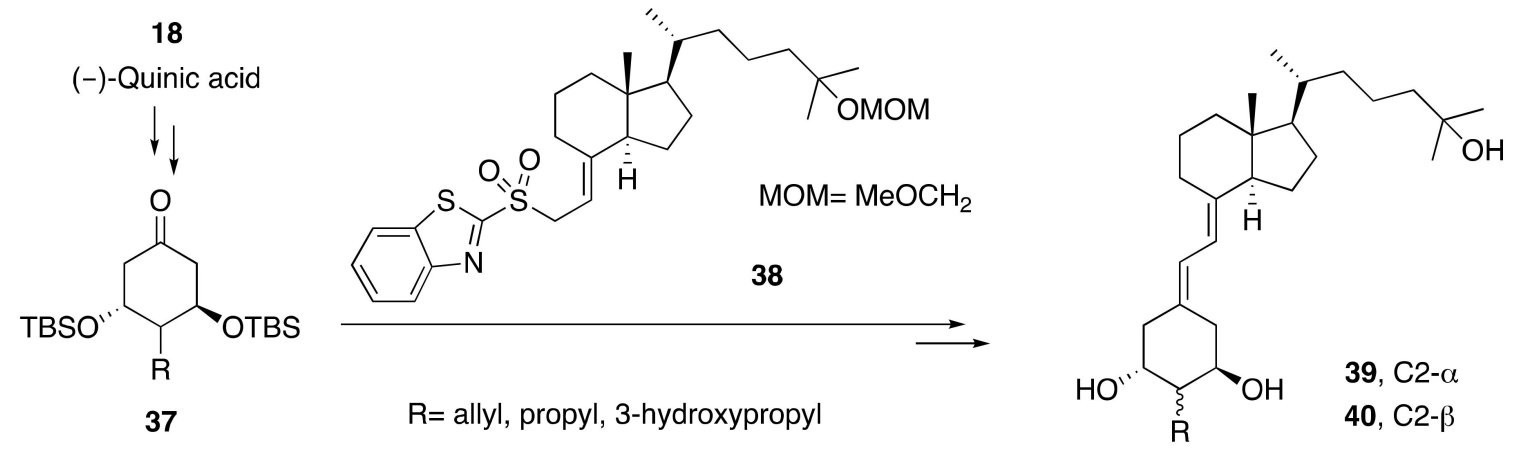

Scheme 8. Preparation of C2-alkyl substituted 1 1 ,25- $(\mathrm{OH})_{2}-19-$ nor-vitamin $\mathrm{D}_{3}$.

A series of singly dehydroxylated 19-nor-1 $\alpha$,25-dihydroxyvitamin $\mathrm{D}_{3}$ A-ring analogs (44-47, Scheme 9) were synthesized by Okano, Mikami, and co-workers [25]. Starting from an aldehyde 41, A-ring synthons $\mathbf{4 2}$ were prepared. The key feature in the syntheses is the stereospecific transformation of the (E)- and (Z)-ene cyclization products into the phosphine oxide 43. Wittig-Horner coupling of the Grundmann's ketone derivative 21 with the former synthon 43 led to the analogs $44-47$. These analogs are useful probes to assess the biological roles of hydroxyl groups at $\mathrm{C} 1$ and $\mathrm{C} 3$ independently.

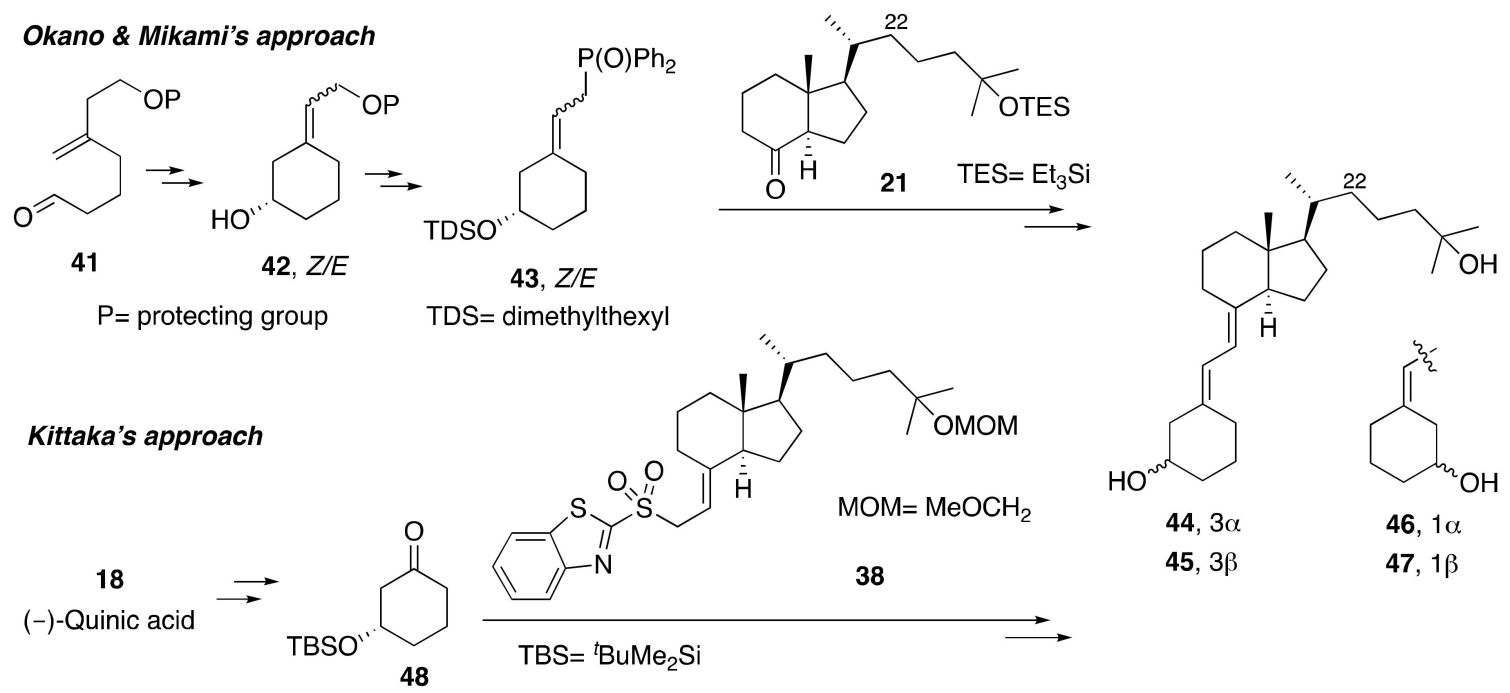

Scheme 9. Preparation of singly dehydroxylated $1 \alpha, 25-(\mathrm{OH})_{2}-19-$ nor-vitamin $\mathrm{D}_{3}$ A-ring analogs.

An alternative approach was presented by Kittaka's group [26] using a new Julia-type olefination. The A-ring precursor 48 (Scheme 9) was synthesized from quinic acid in an enantiomerically pure form. The key step was Julia-type olefination, which proceeded with high yields via the reaction of the ketone $\mathbf{4 8}$ with a sulfone $\mathbf{3 8}$ to form the protected 19-nor-vitamin D derivatives as a 1:1 diastereomeric mixture 45:46.

To establish the conformation of vitamin D compounds responsible for biological activity, a 1 $\alpha, 25$-dihydroxy-19-nor-vitamin D analog 51 (Scheme 10) possessing a $1 \alpha$-hydroxy group fixed in the axial orientation ( $\beta$-chair form) was synthesized by DeLuca's group [27]. The starting material to prepare the A-ring synthon was quinic acid, which was converted to the bicyclic ketones 49 . Julia coupling of the latter with a sulfone 50 produced the 19-nor-vitamin D analog $\mathbf{5 1 b}(n=2)$, which possessed an additional ring connecting the $3 \beta$-oxygen and $C 2$, and the isomeric $3 \beta$-hydroxy compound $\mathbf{5 2} \mathbf{b}(n=2)$. Similar analogs 51a and 52a $(n=1)$, with even more rigid conformation, were also described [28]. The bicyclic fragment $49 \mathbf{a}(n=1)$, which was obtained using a ring-closing metathesis process, reacted with the sulfone 50 in Julia coupling conditions to yield derivatives 51a and 52a. Unexpectedly, these compounds exhibited a calcemic response, probably due to their metabolic conversion in living organisms. To verify this hypothesis, DeLuca and co-workers [29] focused their 
attention on preparing analogs in which the additional ring possessed only carbon units (55 and 56 ). To obtain the latter compounds, a similar procedure to that above was followed with Grundmann's ketone $\mathbf{5 4}$ and the A-ring synthon $\mathbf{5 3}$ that comes from (-)-quinic acid in a multi-step synthesis.
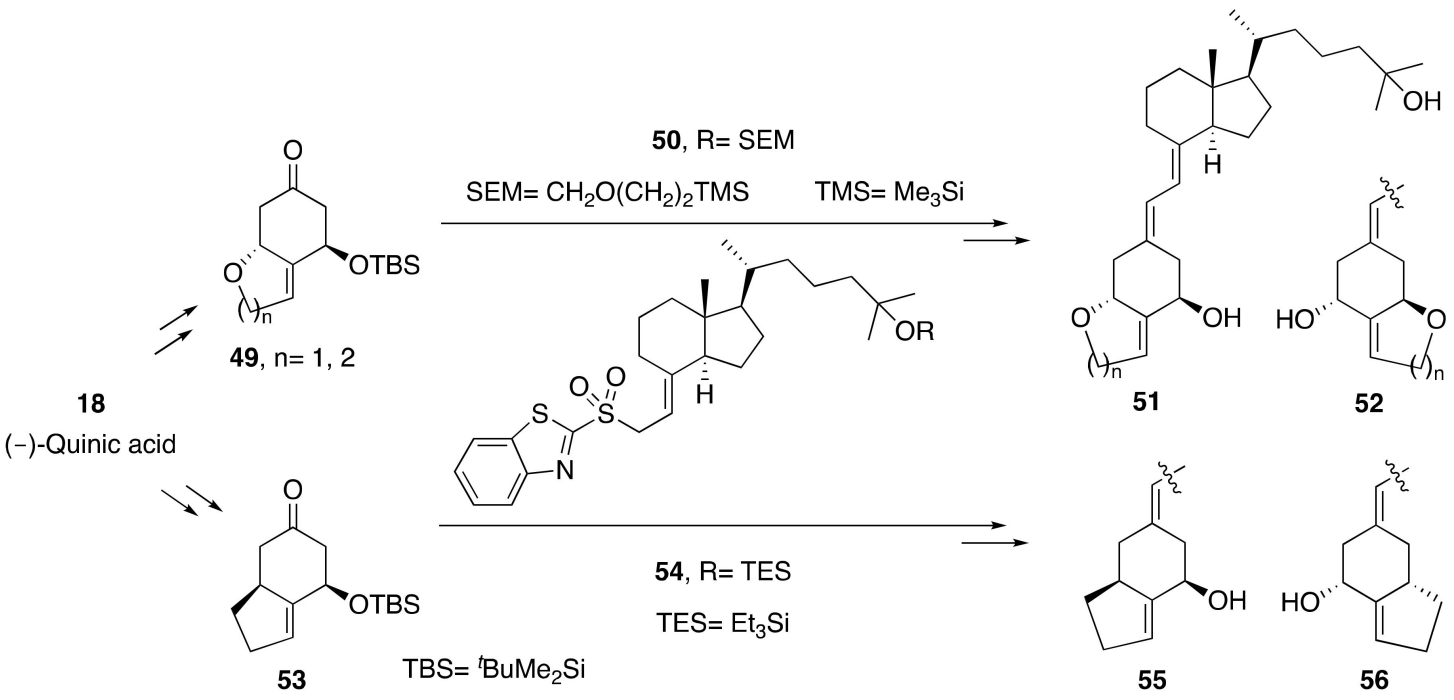

Scheme 10. Synthesis of 19-nor-vitamin $\mathrm{D}_{3}$ analogs with a frozen A-ring conformation.

Because of the importance of A-ring stereochemistry in the biological responses, we previously described [30] an improved method to synthesize of C2-hydroxy (64-69, Scheme 11) and C2,C3- or C1,C2-epoxi-substituted (70,71) 1 $\alpha, 25$-dihydroxy-19-nor-vitamin $\mathrm{D}_{3}$ analogs with different configurations of the A-ring at C1, C2, and C3. A-Ring synthon precursors 60-62 were prepared from methyl quinate and its 3-epi and 5-epi-isomers. The CD-ring/side chain fragment 63 was derived from Grundmann's ketone by oxidizing the 25-position and then protecting the hydroxyl group as ethoxymethyl ether (EOM). Modified Julia olefination between the ketones 60-62 and the sulfone $\mathbf{6 3}$ yielded the vitamin D analogs 64-71.

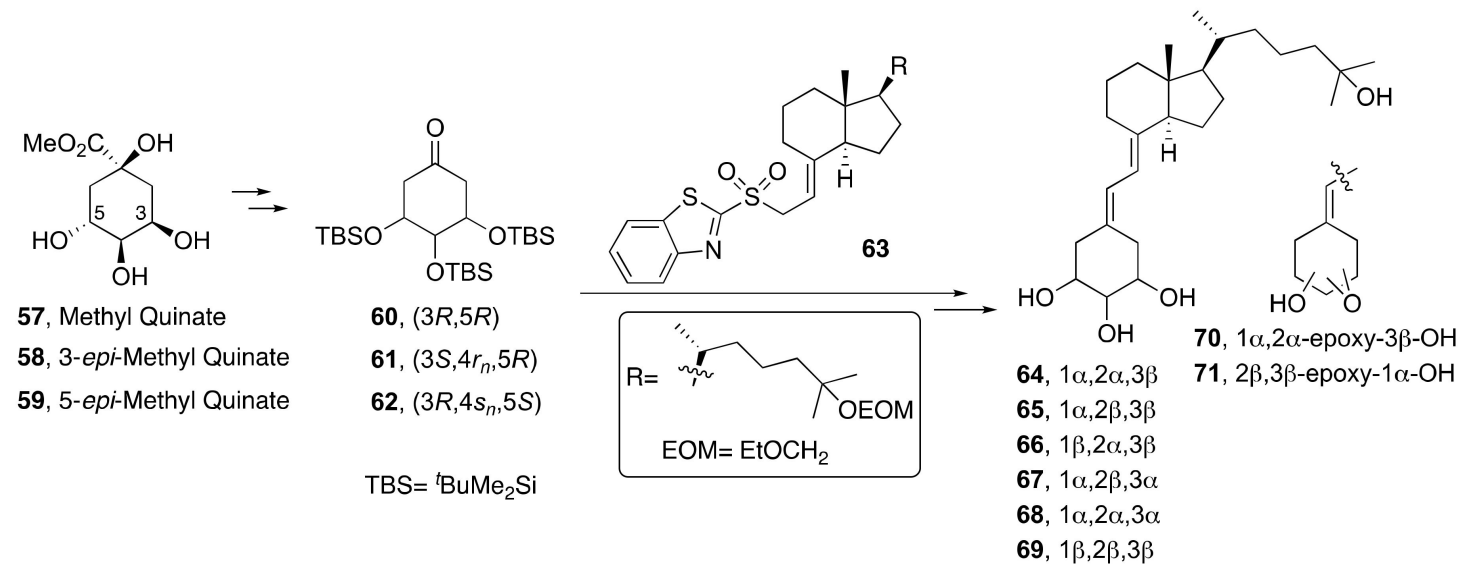

Scheme 11. Preparation of trihydroxylated and epoxides of $1 \alpha, 25-(\mathrm{OH})_{2}$-19-nor-vitamin $\mathrm{D}_{3}$ A-ring analogs.

It has been reported that the introduction of a phosphonate group to the upper side chain of vitamin D analogs reduces their calcemic effects. With the aim to test the effects on VDR binding affinity and hypercalcemic properties, phosphorus-bearing A-ring derivatives were designed. A highly convergent synthesis of four 19-nor-vitamin $\mathrm{D}_{3}$ cyclic phosphates (75-78, Scheme 12) was achieved [31] via a reaction of a sulfonate $\mathbf{7 3}$ with a CD-ring allyl chloride $\mathbf{7 4}$. The A-ring synthon precursor $\mathbf{7 3}$ was synthesized from an achiral dienyl sulfone $\mathbf{7 2}$ as the preliminary starting material, which was prepared on a kilogram scale. 


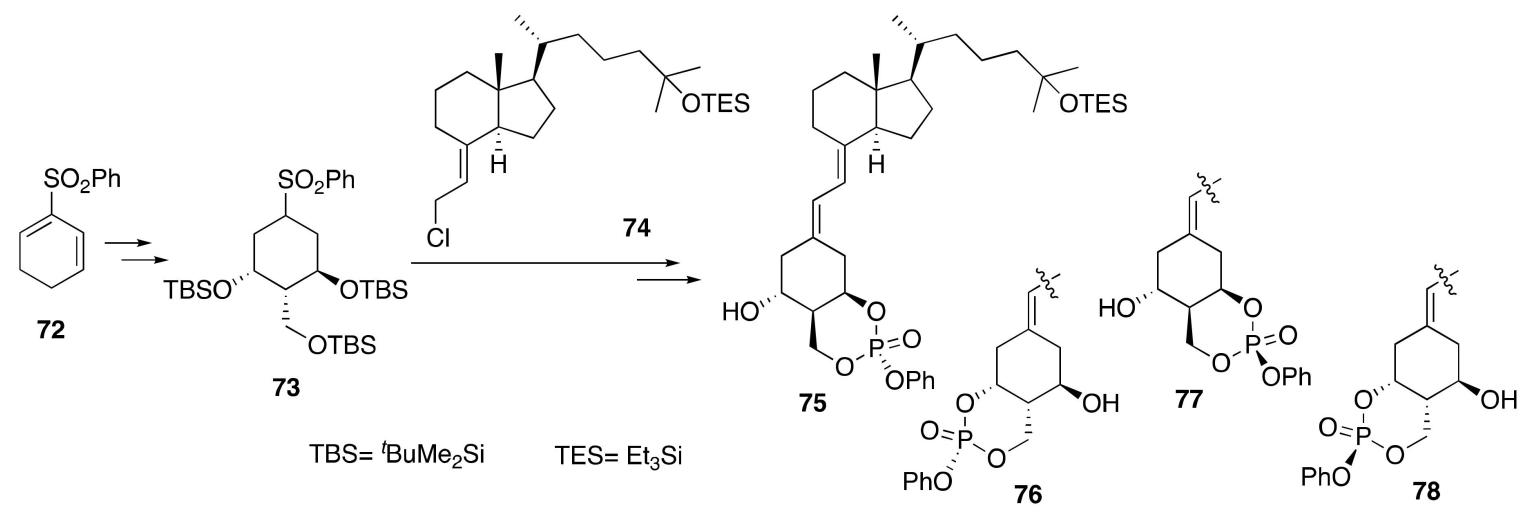

Scheme 12. Preparation of $C 2$ cyclic phosphate $1 \alpha, 25-(\mathrm{OH})_{2}-19-n o r$-vitamin $\mathrm{D}_{3}$ A-ring analogs.

Okamoto and co-workers [32] developed a synthetic method for preparing 2-hydroxy-type A-ring precursors 81 (Scheme 13) via a common intermediate 80 from D-lyxose (79). This involved a Ti(II)-mediated ene-yne cyclization and a Ru-carbene-catalyzed ene-yne metathesis followed by a Ni-catalyzed regioselective hydroboration of the 1,3-diene as the key-step reactions. The resulting A-ring moiety, containing 1,2,3-triol functionality, can be selectively silyl-protected to produce 1,3-di(silyloxy)-2-hydroxy products, which are useful for further manipulation at the C2-position.

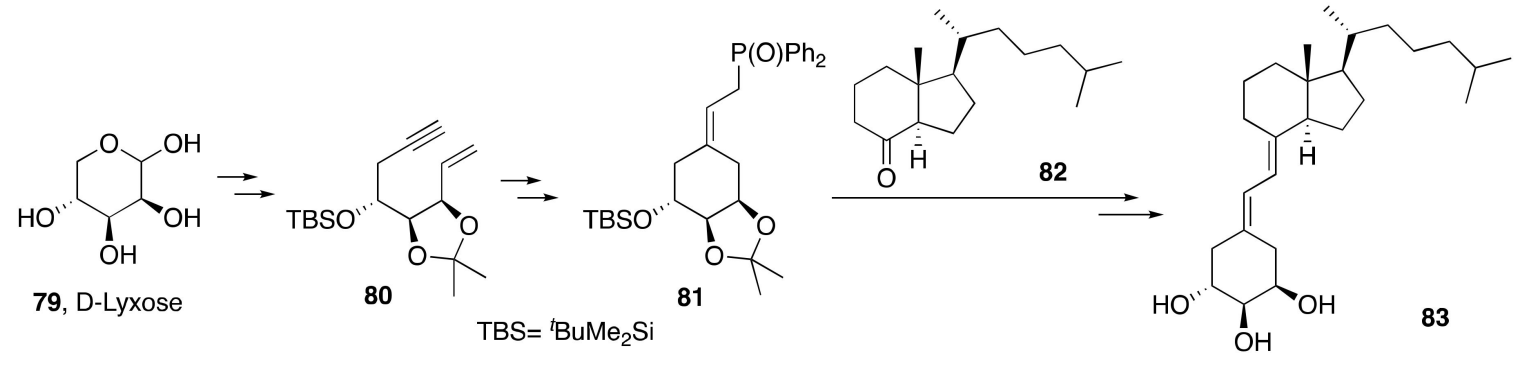

Scheme 13. Preparation of trihydroxy $1 \alpha, 2 \beta-(\mathrm{OH})_{2}-19-$ nor-vitamin $\mathrm{D}_{3}$.

Our laboratory recently reported [33] structurally simple but synthetically challenging A-ring epimers at $\mathrm{C} 1$ and $\mathrm{C} 3$ of the $1 \alpha, 25-(\mathrm{OH})_{2}-19$-nor-vitamin $\mathrm{D}_{3}$ (Scheme 14). These 19-nor analogs had not been described previously, probably because the structure is difficult to elucidate. These analogs (1-epi86 and 3-epi-1 $\alpha, 25-(\mathrm{OH})_{2}-19-$ nor- $\left.-\mathrm{D}_{3} 85\right)$ were synthesized via a convergent synthesis starting from cis,cis-1,3,5-cyclohexanetriol (19), a commercially available compound, and the protected 25-hydroxy Grundmann's ketone $\mathbf{6 3}$. Modified Julia olefination between a ketone 84 and sulfone $\mathbf{6 3}$ gave rise to the target compounds $\mathbf{8 5}$ and $\mathbf{8 6}$. An alternative synthesis using an orthogonally protected intermediate was necessary to unambiguously assign the corresponding structures to each diastereoisomer by NMR spectroscopy. The key step was the biocatalytic desymmetrization of the mono-TBDPS-protected derivative of cis,cis-1,3,5-cyclohexanetriol.

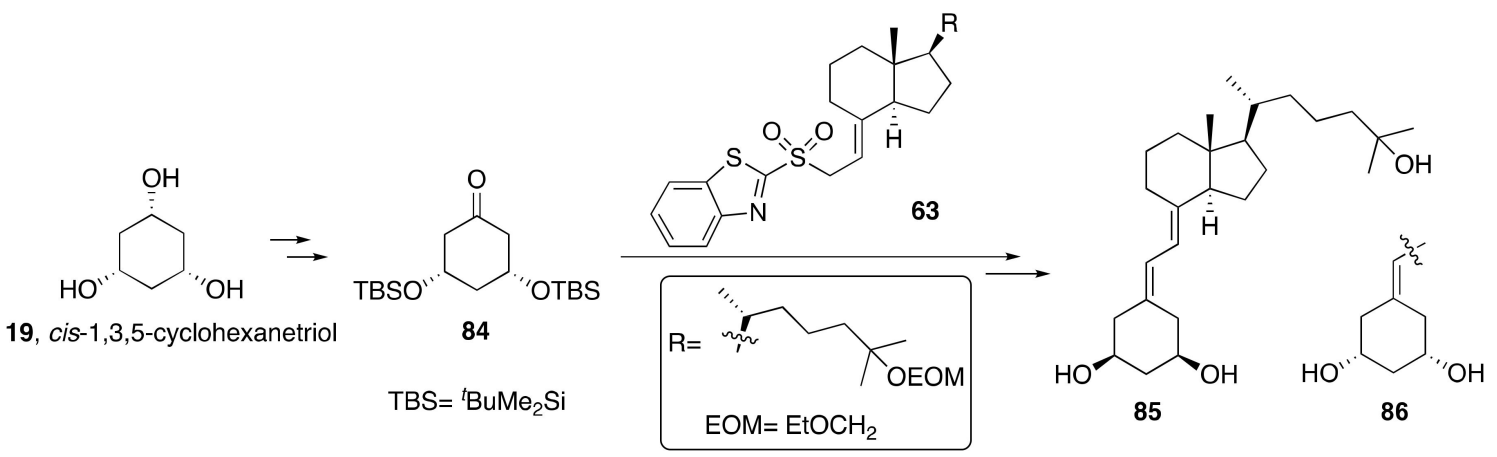

Scheme 14. Preparation of $1 \alpha, 25-(\mathrm{OH})_{2}$-19-nor-vitamin $\mathrm{D}_{3}$ A-ring C1- and C3-epi analogs. 


\subsection{Synthesis of A-Ring- and Diene-Modified Analogs}

Takayama's research group [34] focused on the modification of the A-ring and diene moieties in the 19-nor skeleton. Thus, they described the synthesis of new $1 \alpha, 25$-dihydroxy-19-nor-vitamin $\mathrm{D}_{3}$ analogs 90 (Scheme 15), which have an amide bond in the molecule instead of the diene. The A-ring moiety was substituted with a piperidine ring that has two hydroxyls at $\mathrm{C} 1 \alpha$ and $\mathrm{C} 3 \beta$ with the appropriate stereochemistry. The A-ring synthons 88 were obtained from D-mannose (87), and the CD-ring carboxylic acid 89 was synthesized from Grundmann's ketone. Subsequent condensation of $\mathbf{8 9}$ with the piperidine derivatives $\mathbf{8 8}$ provided the amides $\mathbf{9 0}$ in good yields after deprotection of the silyl groups. This strategy can be applied in combinatorial chemistry; therefore, these compounds would be applicable as useful tools in the development of new drugs.<smiles>C=CC#CC</smiles>

87, D-Mannose

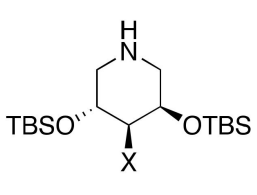

88 $\mathrm{X}=\mathrm{H}, \mathrm{OH}, \mathrm{O}\left(\mathrm{CH}_{2}\right)_{3} \mathrm{OTBS}$

TBS $={ }^{\mathrm{t}} \mathrm{BuMe}_{2} \mathrm{Si}$

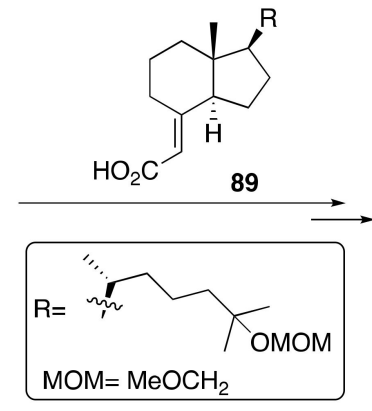

Scheme 15. Preparation of $1 \alpha, 25-(\mathrm{OH})_{2}$-19-nor-vitamin $\mathrm{D}_{3} \mathrm{C} 2$-substituted amide A-ring analogs.

Hadden and co-workers [35] conducted a structure-activity relationship study using a series of vitamin $\mathrm{D}_{3}$-based analogs with aromatic A-ring mimics that resulted in potent, selective Hedgehog pathway inhibition. Thus, they reported the synthesis of aromatic A-ring modified derivatives containing single or multiple substitutions in the aromatic A-ring (91 and 92, Scheme 16) or a heteroaryl or biaryl moiety (93). As precursors of A-ring synthons 91-93, commercially available aromatic acids and esters were purchased and either coupled directly to $\mathbf{9 4}$ or coupled following standard protection/hydrolysis strategies.

Mono-, di- and trisubstituted aromatic A-ring synthons

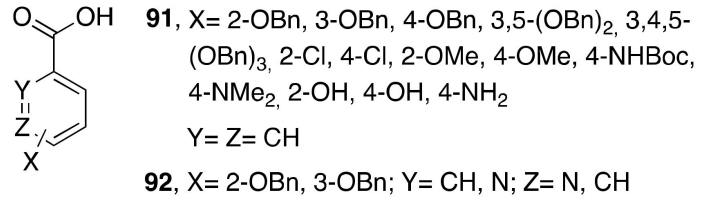

Hetero- and Biaryl A-ring synthons

93, 2-pyridine, 3-pyridine, 4-pyridine, 2-furyl, 3-furyl, 2-thiophenyl, 3thiophenyl, 1-naphthyl, 2-naphthyl, 6-OBn-1-naphthyl, 6-OBn-2naphthyl, 6-OH-1-naphthyl, 6-OH-2-naphthyl, $1 \mathrm{H}$-indole-2-carbonyl

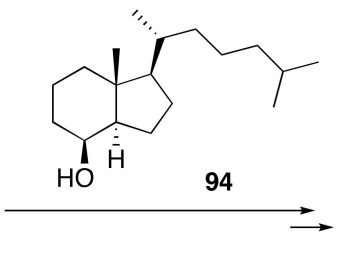

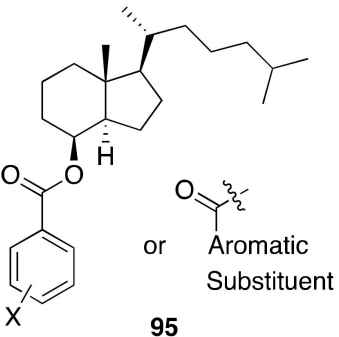

95

Scheme 16. Preparation of $1 \alpha, 25-(\mathrm{OH})_{2}-19$-nor-vitamin $\mathrm{D}_{3}$ analogs with an aromatic A-ring.

\subsection{Synthesis of A-Ring-, D-Ring-, and Side-Chain-Modified Analogs}

To further investigate the effects of the A-ring modification of 16-ene-22-thia-26,27-dimethyl19-nor-vitamin $\mathrm{D}_{3}$ analogs $98(\mathrm{X}=\mathrm{Y}=\mathrm{H} ; n=2,3$; Scheme 17) on the biological activity profile, novel 22-thia-19-nor-vitamin D analogs bearing a hydroxyethoxy-, hydroxyethylidene-, or methyl group at C2 in combination with 20S- and 20R-isomers were prepared and tested by Ito and co-workers [36]. For the synthesis of 2-substituted-16-ene-22-thia-19-nor-vitamin D analogs 98, they employed a Wittig-Horner coupling of the appropriately substituted A-ring phosphine oxides 96, prepared from D-glucose, with the 25-hydroxy Grundmann's ketone derivatives 97. 
<smiles>CC#CC</smiles>

32, D-Glucose

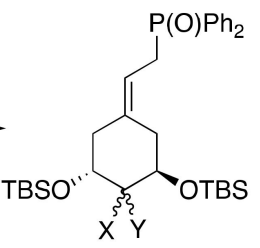

96, C2- $\alpha$ or $C 2-\beta$

$\mathrm{X}$ or $\mathrm{Y}=\mathrm{Me}, \mathrm{OTMS}$ $\mathrm{X}=\mathrm{H} ; \mathrm{Y}=\mathrm{OTMS}$

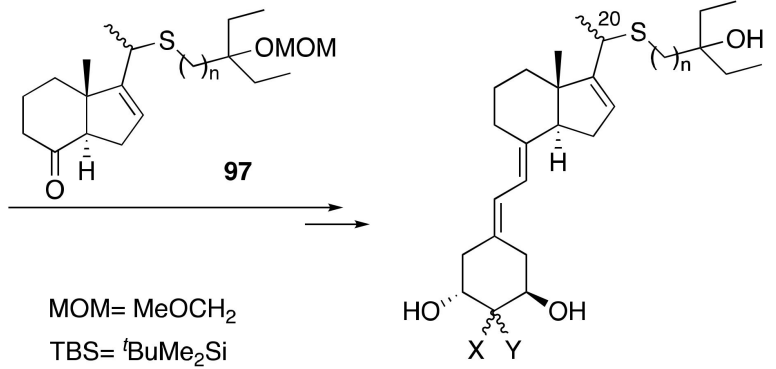

98, C2- $\alpha$ or $\mathrm{C} 2-\beta ; n=1,2,3 ; 20 R$ or $20 \mathrm{~S}$

$\mathrm{X}=\left(\mathrm{CH}_{2}\right)_{2} \mathrm{OH}, \mathrm{OH}, \mathrm{Me} ; \mathrm{Y}=\mathrm{Me}, \mathrm{OH}$ $\mathrm{XY}=(Z)$ or $(E) \mathrm{HOCH}_{2} \mathrm{CH}=$

Scheme 17. Synthesis of $1 \alpha, 25-(\mathrm{OH})_{2}$-19-nor-vitamin $\mathrm{D}_{3}$ analogs with A-ring, D-ring, and side-chain modifications.

\subsection{Synthesis of A-Ring-, CD-Ring-, and Side-Chain-Modified Analogs}

Vandewalle's group [37] reported a practical method to synthesize of (2S,3aS,4aS)-2-tertbutyldimethylsilyloxybicyclo[3.1.0] hexane-3a-carbaldehyde (101, Scheme 18) and diastereoisomers (102-104), starting from all-cis methyl 3,5-dihydroxy-1-cyclohexanecarboxylate (99). The key step was the asymmetrization of $\mathbf{9 9}$ by an enzyme-catalyzed transesterification, which afforded crystalline enantiopure $\mathbf{1 0 0}$ in high yield. Several chemical transformations led to cyclovitamin A-ring precursors 101-104, which were coupled with appropriate cis-hydrindane 105 to produce the 14-epi-19-nor vitamin $\mathrm{D}_{3}$ analogs 106. This method is applicable to the large-scale production.
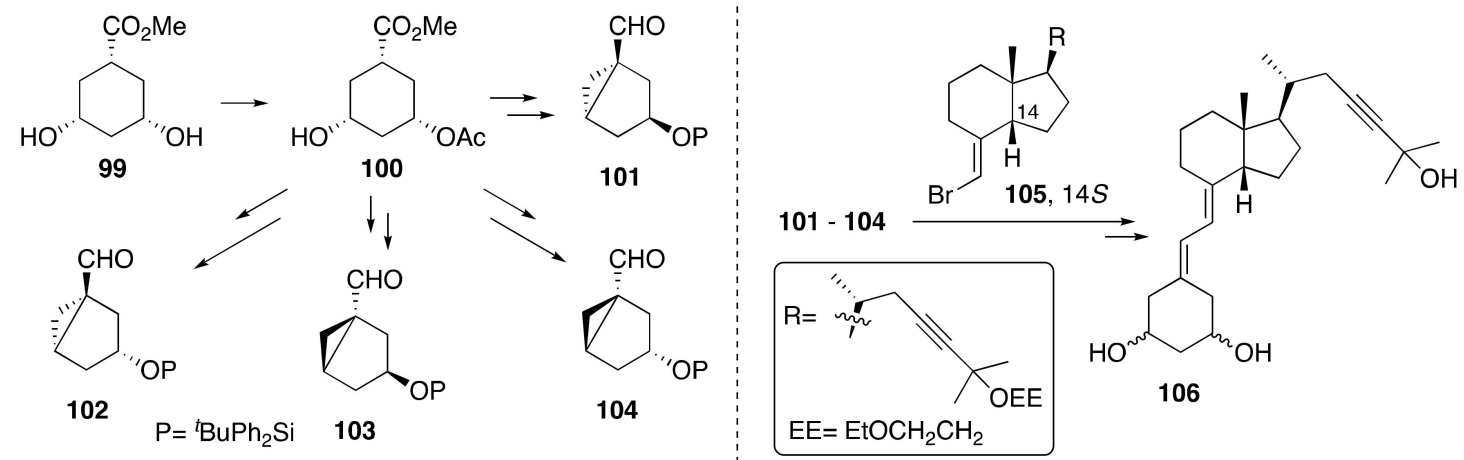

Scheme 18. Synthesis of $1 \alpha, 25-(\mathrm{OH})_{2}-19-$ nor-vitamin $\mathrm{D}_{3}$ analogs with A-ring, CD-ring, and side chain modifications.

\subsection{Synthesis of A-Ring- and Side-Chain-Modified Analogs}

The first analogs of this class were reported by Mikami's group [25]. They consist of several singly dehydroxylated 22-oxa- $(1 \alpha), 25-(\mathrm{OH})_{2}-19$-nor-vitamin $\mathrm{D}_{3}$ derivatives with similar structures to those of compounds 44-47 (Scheme 9) in which the $\mathrm{CH}_{2}$ in the 22-position was replaced by an oxygen atom. Their syntheses were similar to that described in Scheme 9 but with the corresponding 22-oxa-CD-ring/side chain synthon of 21 . These analogs were synthesized since little information was available concerning the structural motifs of the $1 \alpha, 25-(\mathrm{OH})_{2}-\mathrm{D}_{3}$ hormone responsible for the modulation of differentiation and apoptosis.

Another family of compounds was described by DeLuca's group [20]. Their structure is similar to that of product 35a ( $\mathrm{R}=\mathrm{H}$, Scheme 7$)$ but with the unnatural $20 S$ configuration. The latter compound, named 2MD ((20S)-1 $\alpha$,25-dihydroxy-2-methylene-19-nor-vitamin $\left.\mathrm{D}_{3}\right)$, showed a unique ability to induce bone formation and has proven anabolic for bone in in vivo studies, but it has a tendency to cause hypercalcemia because of its bone calcium mobilizing activity. For this reason, DeLuca and co-workers [38] prepared several derivatives of 2MD 109 (Scheme 19). Thus, the 18-nor, 21-nor, and 18,21-dinor analogs of 2MD 109 were prepared by convergent syntheses. The known phosphine oxide 
34a, obtained from quinic acid, was coupled by the Wittig-Horner process with the corresponding CD-ring/side chain fragments 108, obtained by a multi-step procedure from commercial vitamin $\mathrm{D}_{2}$ (107).
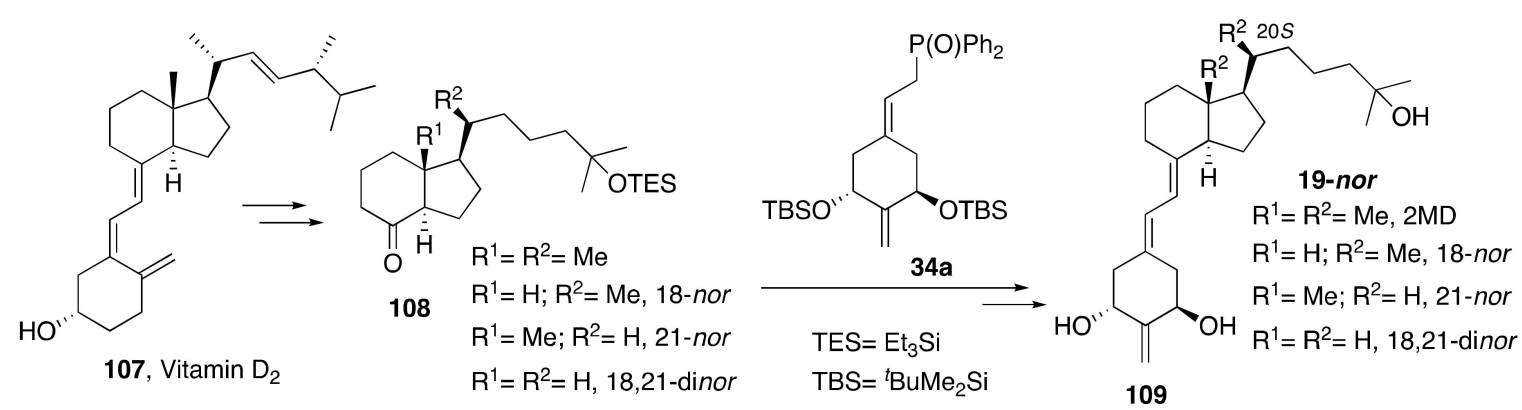

Scheme 19. Synthesis of $2 \mathrm{MD}$ nor and dinor derivatives of $1 \alpha, 25-(\mathrm{OH})_{2}-19-$ nor-vitamin $\mathrm{D}_{3}$.

Mikami and co-workers showed the synthesis of hybrid analogs of 2-methyl- (113a) [39] and 2-fluoro-22-oxa-1 $\alpha, 25-(\mathrm{OH})_{2}-19-n o r-\mathrm{D}_{3}(\mathbf{1 1 3 b})$ [40] (Scheme 20). One of the reasons that they synthesized fluorinated A-ring analogs was to investigate the VDR-binding conformation of the A-rings on the basis of ${ }^{19} \mathrm{~F}$ NMR analysis. The A-rings 111 were synthesized via asymmetric catalytic carbonyl-ene cyclization from aldehydes 110. Subsequently, a fluorine A-ring synthon $\mathbf{1 1 1}$ was synthesized via the highly regio- and stereoselective epoxide-opening $2 \alpha$-fluorination and catalytic asymmetric carbonyl-ene cyclization [41]. Lythgoe coupling of the 22-oxa-CD-ring/side chain 112 with the Wittig reagents 111 led, via desilylation, to C2-methyl and C2-fluoro-1 $\alpha, 25-(\mathrm{OH})_{2}-19-$ nor- $\mathrm{D}_{3}$ analogs 113.
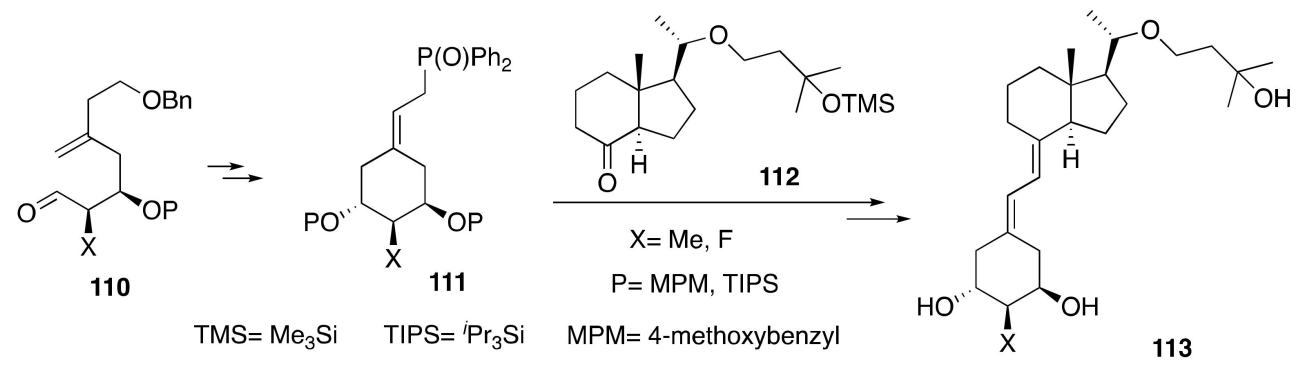

Scheme 20. Synthesis of C2-methyl and C2-fluoro 22-oxa- $1 \alpha, 25-(\mathrm{OH})_{2}-19$-nor-vitamin $\mathrm{D}_{3}$ derivatives.

In light of previously reported data, there was an interest in preparing vitamin $\mathrm{D}$ derivatives with more potent calciotropic activity than that of the natural hormone because of their potential use in the treatment of osteoporosis. DeLuca and co-workers [21] became interested in the exploration of the effect of the side chain structure on the activity of 2-methylene and 2-methyl substituted analogs. Thus, they described multiple modified analogs similar to 35 and 36 shown in Scheme 7, the only difference is in the stereochemistry at C20. Instead of just the natural configuration (C20R), they also obtained epimers, that is, C20S. They also prepared [42] 2-substituted (20S)-1 $\alpha, 25$-dihydroxy-19-nor vitamin $\mathrm{D}_{3}$ analogs 115 and 116 (Scheme 21) with elongated side chains by Wittig-Horner coupling of an A-ring phosphine oxide 34a with the corresponding protected (20S)-25-hydroxy Grundmann's ketones 114. 


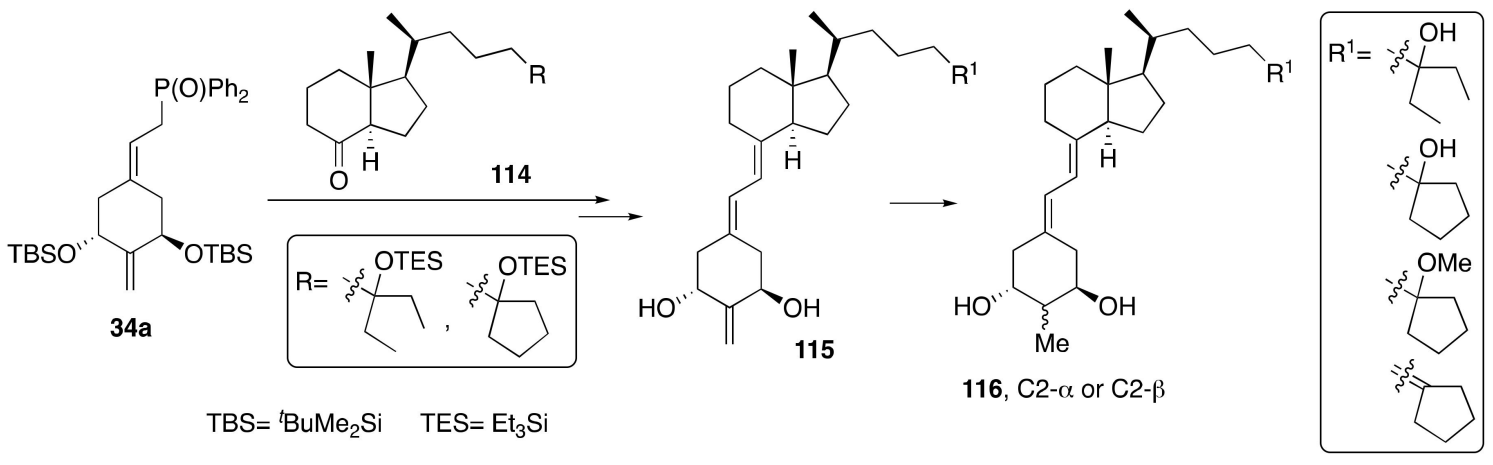

Scheme 21. Synthesis 2-substituted side-chain-modified (20S)-1 $\alpha, 25-(\mathrm{OH})_{2}-19$-nor-vitamin $\mathrm{D}_{3}$.

Using their procedure, DeLuca's group synthesized C2-substituted $1 \alpha-\mathrm{OH}-19-$-nor-vitamin $\mathrm{D}_{3}$ with C20S alkyl side chains (Scheme 22). They prepared an abbreviated [43], 25-methyl substituted, and normal side chain containing no hydroxyl group [44]. The key step in the synthesis was the Wittig-Horner olefination of Grundmann's ketones 118 possessing different $17 \beta$-alkyl substituents, with the phosphine oxide 34a prepared from (-)-quinic acid. The corresponding CD fragment 118 was obtained from the known Inhoffen-Lythgoe diol 117, which is easily obtained from vitamin $\mathrm{D}_{2}(\mathbf{1 0 7})$. The coupling of ketones 118 with the anion generated from 34a, followed by hydroxyl deprotection, generated the corresponding 2-methylene-19-nor-vitamins 119 and, after homogeneous catalytic hydrogenation, provided 2- $\alpha / \beta$-methyl-19-nor-vitamins 120. On the other hand, 19-nor-vitamins 121 possessing a $3^{\prime}$-hydroxypropylidene fragment attached to $C 2$ and shortened $17 \beta$-alkyl chains have also been reported [45]. The hydrindanones $\mathbf{1 1 8}$ were subjected to a reaction with the phosphine oxide 34c, and the vitamin D compounds 121 were obtained after hydroxyl deprotection.

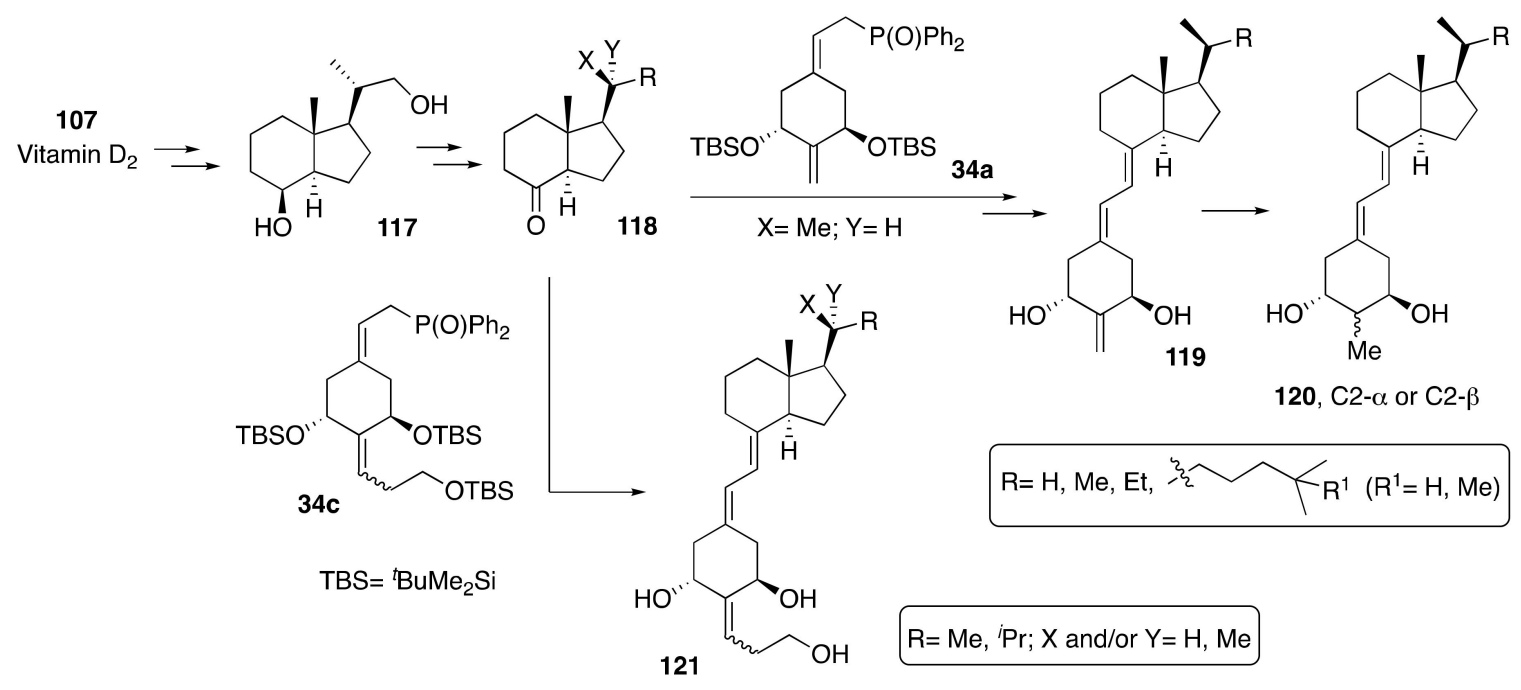

Scheme 22. Synthesis of C2-substituted $1 \alpha-\mathrm{OH}-19$-nor-vitamin $\mathrm{D}_{3}$ with shortened side chains.

To further examine the effects on binding affinity to VDR as well as the transcriptional activity of 2-substituted 19-nor-vitamin D analogs, Shimizu and coworkers [46-48] synthesized new 2-substituted and side-chain-modified 19-nor-1 $\alpha, 25-(\mathrm{OH})_{2}-\mathrm{D}_{3}$ derivatives. 25-Hydroxy-protected Grundmann's ketones 122 (Scheme 23) were treated with ( $3 R, 5 R)-3,4,5$-trihydroxy A-ring phosphine oxide derivatives 123, which were synthesized enantioselectively from D-glucose, to generate vitamin D intermediates 124. The latter compounds were unprotected at C2-OTMS and oxidized to ketones and, after several transformations, yielded 2-hydroxyethylidene derivatives $125(\mathrm{X}=\mathrm{OH})$ or 2-fluoroethylidene analogs $125(X=F)$ as a 1:1 mixture of $E$ - and Z-isomers. OTMS-unprotected derivatives of $\mathbf{1 2 4}$ were allowed to react with 2-bromoethanol TBS ether, and then all protecting groups were removed, yielding the 
analogs 126. Both families of compounds $\mathbf{1 2 5}$ and $\mathbf{1 2 6}$ were also obtained with other side chains starting from the appropriately modified CD-ring/side chain 122.

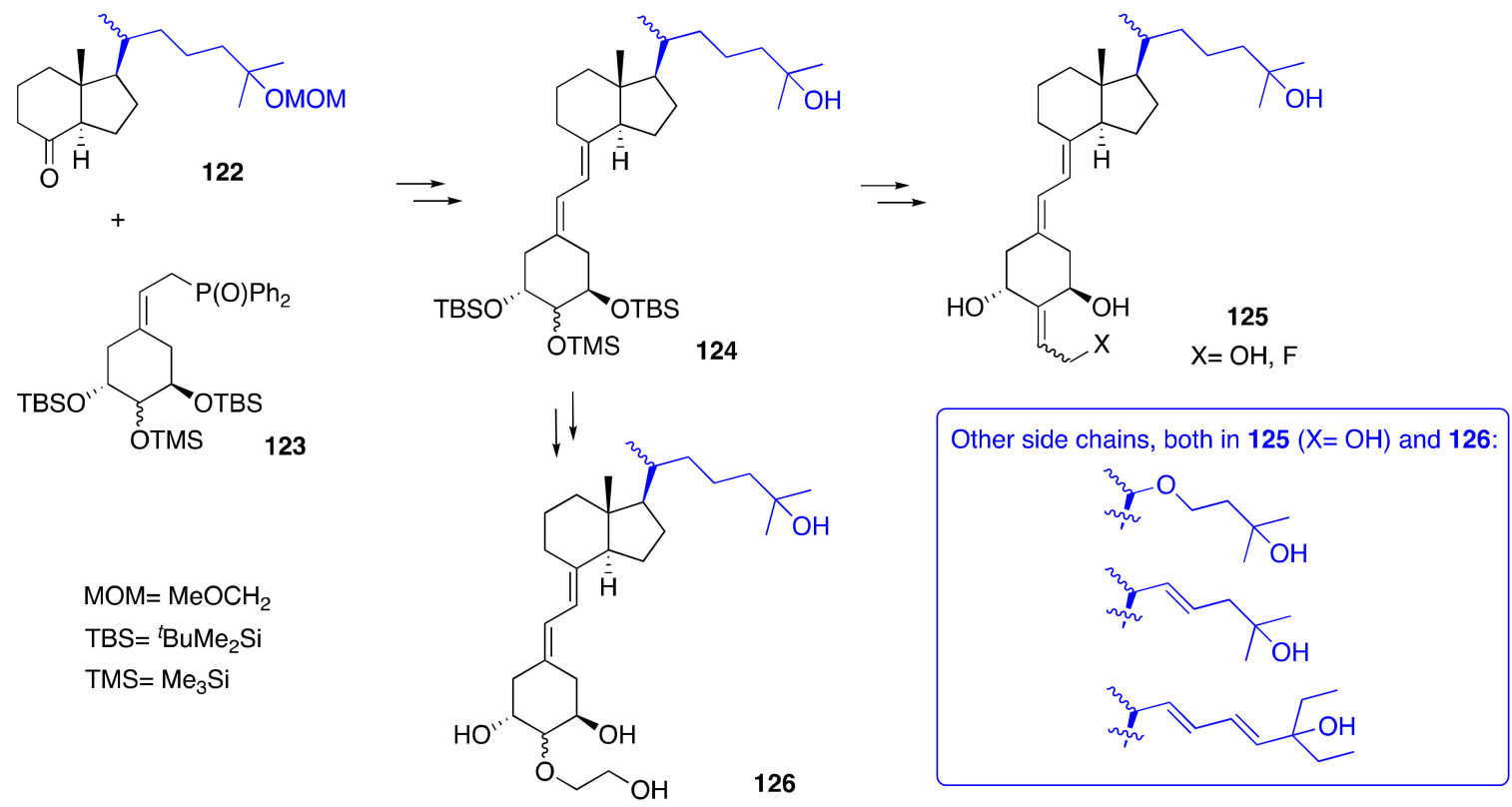

Scheme 23. Synthesis of 2-hydroxy- and 2-fluoroethylidene side-chain-modified analogs of $1 \propto, 25-(\mathrm{OH})_{2}-19-$ nor-vitamin $\mathrm{D}_{3}$.

Posner and co-workers [49] prepared a series 19-nor analogs 130-132 (Scheme 24) of the hormone calcitriol containing a hydroxymethyl group either at the 1-position or at the 3-position. They wanted to determine whether the 19-nor-D derivatives behaved like natural vitamin $\mathrm{D}$ but with even less of a calcemic effect. The synthesis of the A-ring synthons $\mathbf{1 2 8}$ started from readily available 3-cyclohexene-1-carboxylic acid ( \pm )-127. Vitamin D 19-nor analogs $\mathbf{1 3 0 - 1 3 2}$ were prepared through Horner-Wadsworth-Emmons coupling of the corresponding CD-ring ketones $\mathbf{2 4}$ or $\mathbf{1 2 9}$ and A-ring phosphine oxides 128.

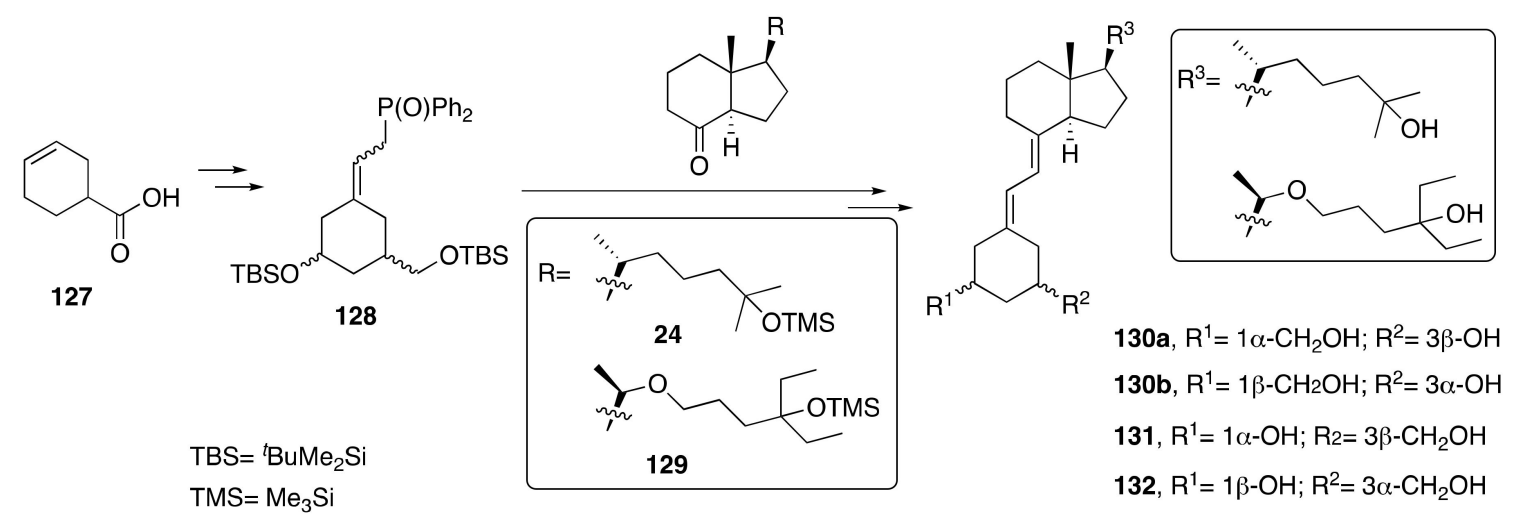

Scheme 24. Synthesis of hydroxymethyl and side chain derivatives of $1 \alpha, 25-(\mathrm{OH})_{2}-19-$-nor-vitamin $\mathrm{D}_{3}$.

To examine the effect of 2,2-disubstitution on the biological activities of 19-nor-vitamin D derivatives, Shimizu's group [50] described the synthesis of novel 2,2-disubstituted-(20R)- and (20S)-19-nor-vitamin $\mathrm{D}_{3}$ analogs 136 and $\mathbf{1 3 7}$ (Scheme 25). For the synthesis of the target 2,2-disubstituted compounds 136-137, they used a Wittig-Horner coupling approach involving the A-ring phosphine oxide 133 with 25-hydroxy Grundmann's ketones possessing a natural $20 R-21$ and an unnatural 20S-134 configuration. Deprotection of compound 135 led to the analogs 136 and, from nucleophilic ring-opening reactions, gave rise to the derivatives 137. 


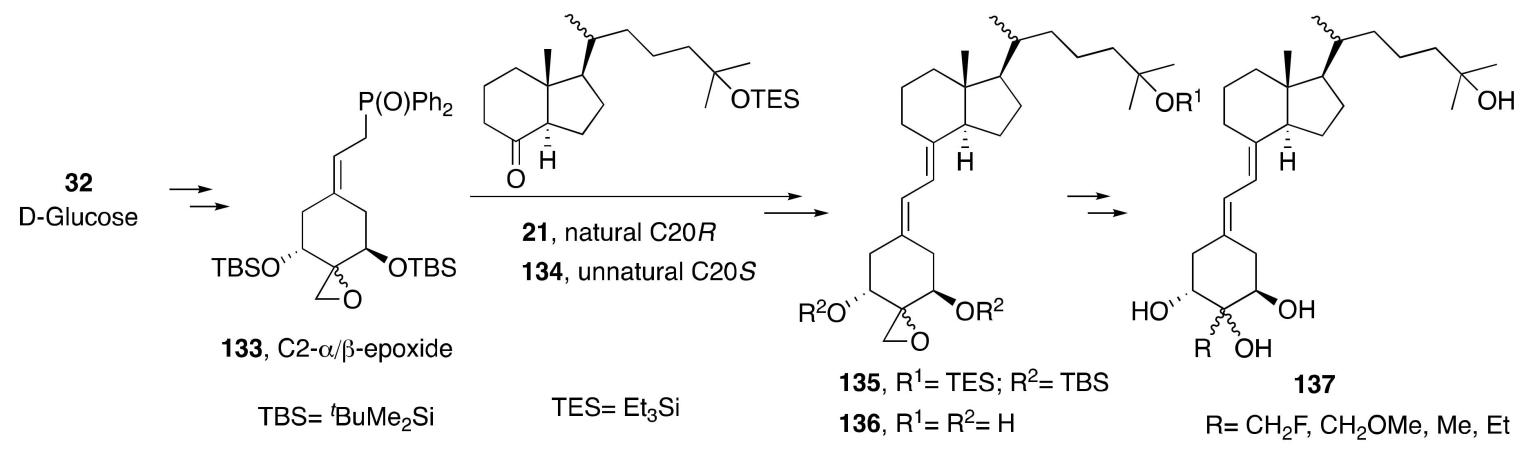

Scheme 25. Synthesis of 2,2-disubstituted-(20R)- and (20S)- $1 \alpha, 25-(\mathrm{OH})_{2}$-19-nor-vitamin $\mathrm{D}_{3}$.

DeLuca's research group [22] described side-chain- and A-ring-modified analogs similar to compounds 35 with the unnatural C20S configuration using the same approach shown in Scheme 7.

Yamada and co-workers [51] synthesized four new vitamin D derivatives 142a (Scheme 26), diastereomers at C20 and C25 of 26-adamantyl-1,25-dihydroxy-2-methylene-22,23-didehydro-19,27dinorvitamin $\mathrm{D}_{3}$, which have a bulky and rigid adamantane ring system at the side chain terminus. Their synthesis was designed to fit into three parts: A side chain fragment with an adamantyl group at the terminal, a 19-nor A ring synthon, and a CD ring plus C22 side chain moiety. The side chain $\mathbf{1 3 9}$ was synthesized from adamantyl ethanol 138a $(m=1)$. C22-Tosylate 140, which was obtained from vitamin $\mathrm{D}_{2}$, was combined with 19-nor-A-ring phosphine oxides 123 to yield 141a after several steps, and then both C22-aldehydes 141a were coupled with the side chain sulfone 139a and, after general functional group transformations, yielded the target vitamin D compounds 142a. Several modifications of the length of the side chain were also reported [52] to generate the analogs $\mathbf{1 4 2} \mathbf{b}-\mathbf{1 4 2 d}$. These compounds have been shown to have a series of partial VDR agonistic/antagonistic activities. The bulky adamantyl side chain produces structural changes that destabilize the active protein conformation and reduce its contribution to equilibrium among the active and inactive conformations.

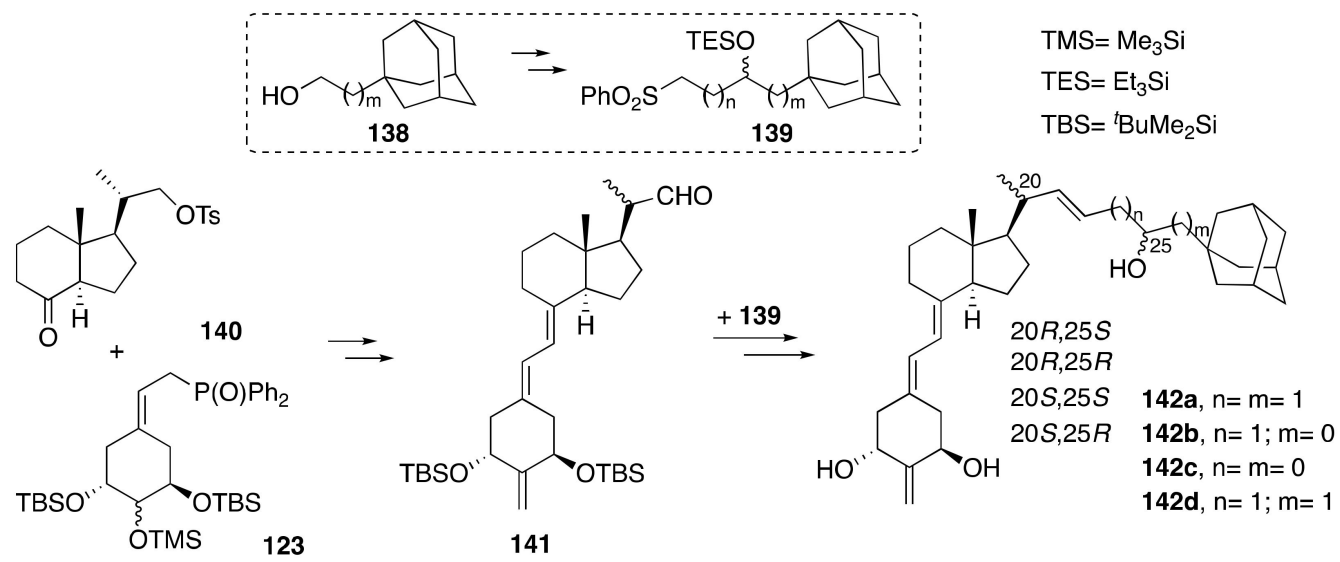

Scheme 26. Synthesis of adamantyl derivatives of $1 \alpha, 25-(\mathrm{OH})_{2}-19-$-nor-vitamin $\mathrm{D}_{3}$.

To investigate the molecular mechanism of VDR antagonists without a structurally bulky group interfering with helix 12 of the ligand-binding domain of the VDR, Yamada and Yamomoto's group reported [53] the synthesis of four diastereomers at $\mathrm{C} 20$ and $\mathrm{C} 23$ of $1 \alpha$-hydroxy-19-nor-vitamin $\mathrm{D}_{3}$ 25-methylene-26,23-lactone bearing a 2MD-type A-ring (145, Scheme 27). The Wittig-Horner reaction of Grundmann's ketone derivatives 143 with A-ring phosphine oxides 123 derived from (-)-quinic acid resulted in the 23-cyanides 144 . Then, the procedure continued with 2-methylenation and subsequent methylene lactonization to yield the lactone analogs 145 . Furthermore, in an effort to explore the pharmacologically important C2-methylene derivatives of 19-nor- $\mathrm{D}_{3}$, DeLuca's group [54] proposed another alternative pathway to synthesize compounds $145 \mathbf{a}, \mathbf{b}$ based on the same coupling approach of 
the Grundmann-type ketone 146 with a phosphine oxide 34a to obtain the coupled product 147, which, after several modifications, allowed them to isolate the analogs $\mathbf{1 4 5 a} \mathbf{a} \mathbf{b}$.

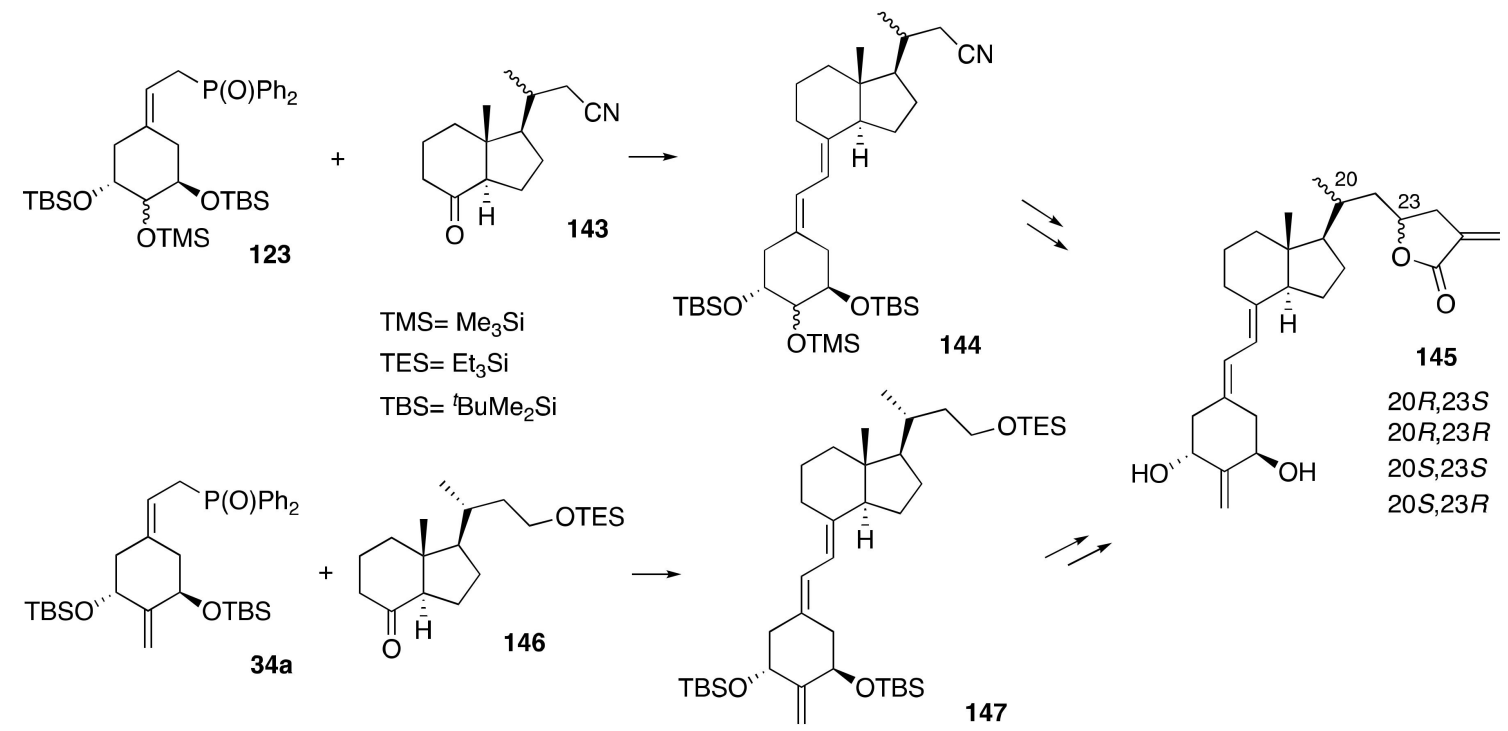

Scheme 27. Synthesis of 25-methylene-26,23-lactone-2-methylene- $1 \alpha-\mathrm{OH}-19$-nor-vitamin $\mathrm{D}_{3}$ analogs.

A series of vitamin $\mathrm{D}_{3}$ analogs with or without a 22-alkyl substituent were synthesized by Yamamoto and co-workers [55] in order to evaluate their biological potency. 1,24- and 1,25Dihydroxyvitamin $\mathrm{D}_{3}$ 22-alkyl derivatives 149 (Scheme 28) were synthesized from the corresponding tosylate 148, which is a convenient synthetic intermediate for various vitamin D side-chain analogs, prepared from the coupling of the A-ring synthon 34a and CD-ring moiety 140. Later, the same group [56] synthesized analogs 149 with a more hydrophobic substituent at the 24-position to determine whether it could enhance VDR activation. Thus, they introduced a diethyl substituent instead of a dimethyl at C24. In addition, DeLuca's group [57] prepared six new analogs of 1 $\alpha, 25$-dihydroxy-19-nor-vitamin $\mathrm{D}_{3} 149$ by a convergent synthesis and applied the Wittig-Horner reaction as a key step using the CD-ring/side chain derivative 150. The objective was to test all possible conformers resulting from C20 epimerization and the introduction of a methyl group at the two available positions on C22. They also used the attachment of two methyl groups on C22 to help elucidate the biological impact of the double substitution of this side chain carbon.
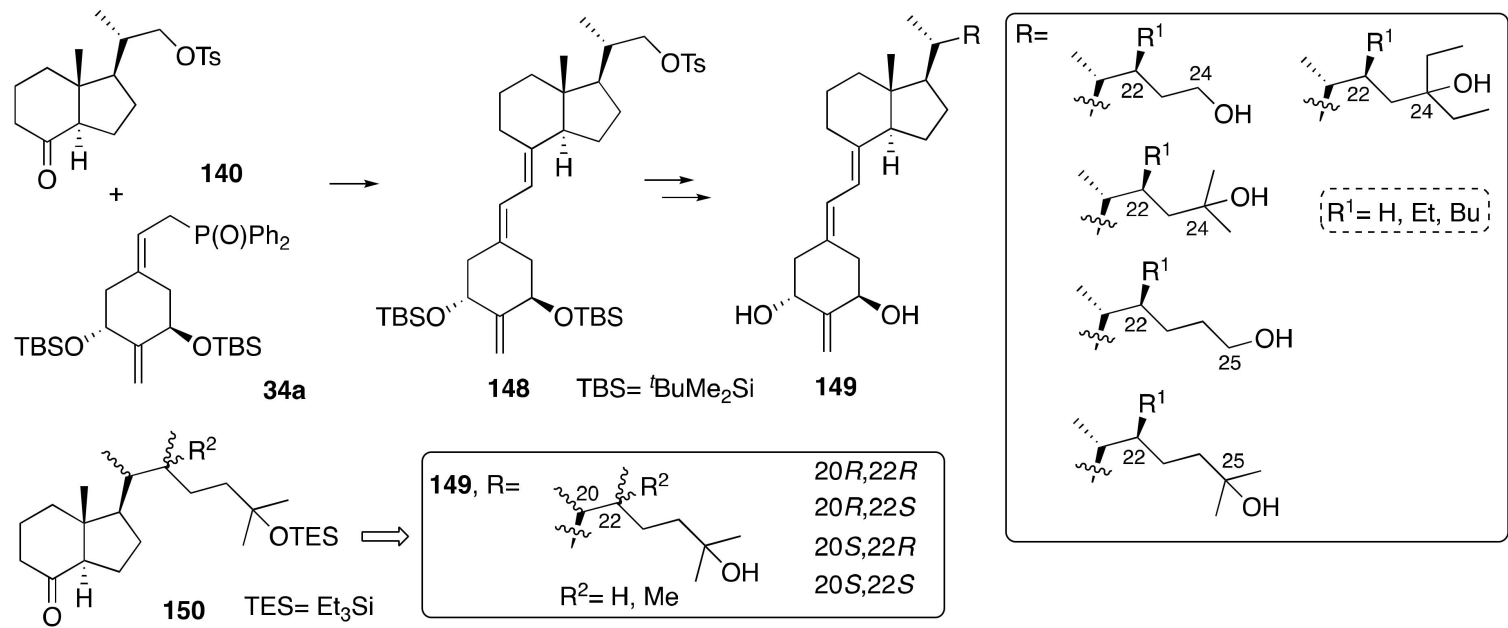

Scheme 28. Synthesis of side chain 2-methylene-1 $\alpha, 25-\mathrm{OH}-19-$-nor-vitamin $\mathrm{D}_{3}$ analogs. 
With the aim to test the influence of removing one [58] or both [59] methyl groups located at C25 on the biological in vitro and in vivo activity, DeLuca's research group prepared 24 new analogs of 19-nor-1 $\alpha, 25-d i h y d r o x y v i t a m i n ~ D_{3}$ (152-155, Scheme 29). To produce these compounds, a convergent approach via a Wittig-Horner reaction between Grundmann's ketone derivatives 151, either possessing fixed configurations of the hydroxyl group at $\mathrm{C} 25(\mathrm{X}=\mathrm{OH})$ or lacking it $(\mathrm{X}=\mathrm{H})$, and the A-ring synthon 34a. These syntheses led to the vitamin D derivatives 152 and 154 after deprotection of the silyl groups. The homogeneous catalytic hydrogenation of the 2-methylene moiety in 152 and 154 provided an equimolar mixture of 2-methyl-19-nor-vitamins 153 and 155, which were easily separated by HPLC.<smiles>[R][C]([X])CCC[C@H](C)[C@H]1CC[C@H]2C(=O)CCC[C@@]21C</smiles>

$\mathrm{R}=\mathrm{H}, \mathrm{Me} ; \mathrm{X}=\mathrm{H}, \mathrm{OH}$

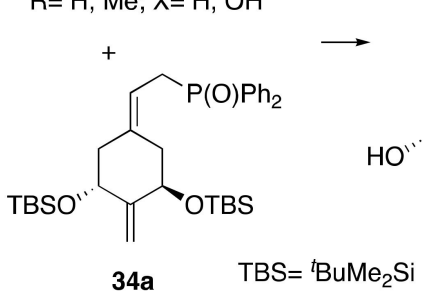<smiles>[Y][C]([R])CCC[C@H](C)[C@H]1CC[C@H]2CCCC[C@@]21C</smiles>

152, $\mathrm{R}=\mathrm{Me} ; \mathrm{X}=\mathrm{OH}$ $20 R, 25 R$ $20 R, 25 S$ 20S,25R 20S,25S

154, $\mathrm{R}=\mathrm{H} ; \mathrm{X}=\mathrm{H}, \mathrm{OH}$ $20 R / S$

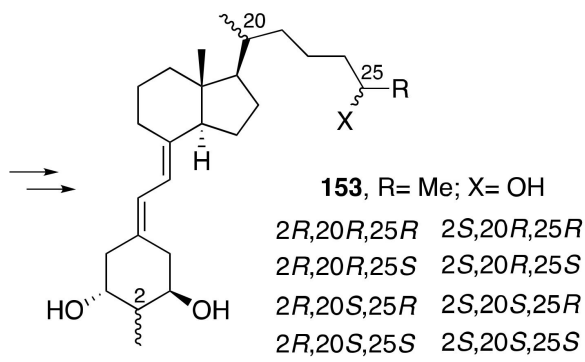

$155, \mathrm{R}=\mathrm{H} ; \mathrm{X}=\mathrm{H}, \mathrm{OH}$ $2 R / S, 20 R / S$

Scheme 29. Synthesis of C25-(di)nor (di)methyl 2-substituted-1 $\alpha, 25-\mathrm{OH}-19-$ nor-vitamin $\mathrm{D}_{3}$ analogs.

Compound (20S)-1 $\alpha$,25-dihydroxy-2-methylene-19-nor-vitamin $\mathrm{D}_{3}$, known as 2MD (2MD was discontinued from the phase II studies in 2011 since it lacked efficacy in increasing bone mineral density in osteopenic postmenopausal women, which is in contrast to its effect in the ovariectomized rats. The discrepancy could be due to the differences in bone metabolism in rats and humans.), significantly enhances calcemic activity and can be used for the treatment of osteoporosis. Therefore, it was of interest to also prepare its 1-desoxy analog 159 (Scheme 30). DeLuca's group [60] reported that the synthesis of 159 by Wittig-Horner coupling of the known protected (20S)-25-hydroxy Grundmann's ketone 108a and the phosphine oxides 157 and 158, which differ in their hydroxyl protection, provided the target 1-desoxy-2MD (159) after removal of the silyl protecting groups. Starting from commercially available compounds [1,4-cyclohexanedione monoethylene acetal 156 and (-)-quinic acid 18)], two different routes were designed that led to both A-ring synthon precursors.

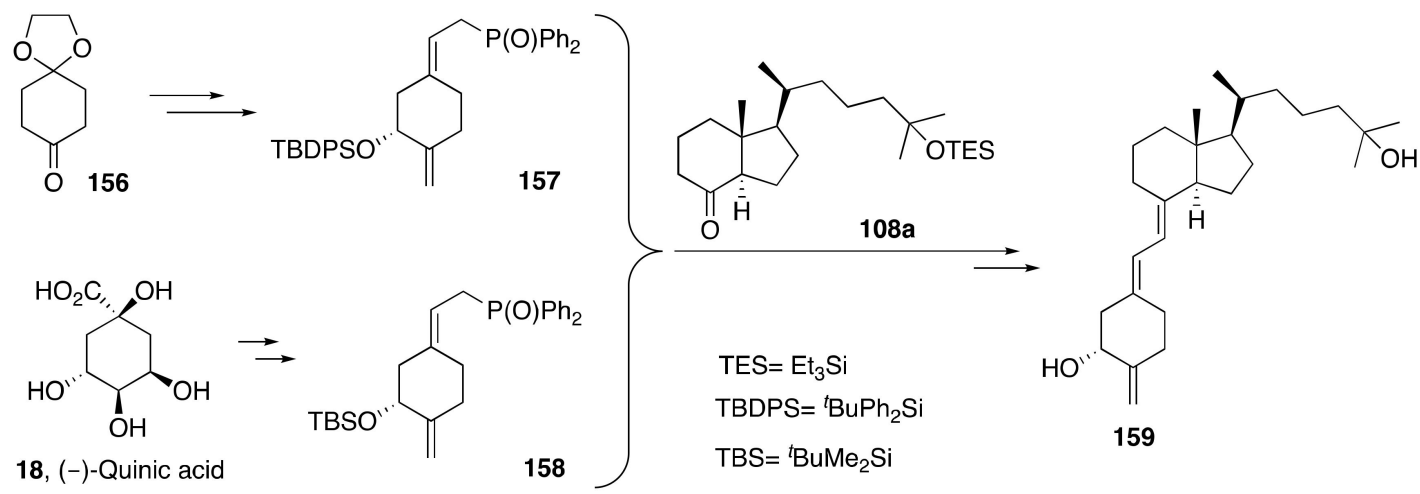

Scheme 30. Synthesis of (20S)-25-hydroxy-2-methylene-19-nor-vitamin $\mathrm{D}_{3}$.

A novel vitamin D receptor agonist 163 (Scheme 31) was synthesized by Wu-Wong and co-workers [61]. Preparation of A-ring diphenylphosphine oxide 34a was obtained from a ketone 162, which is easily available from commercial (-)-quinic acid. The CD-ring/side chain moiety 161 was 
prepared from the ketone 160 , which was ultimately obtained from vitamin $\mathrm{D}_{2}$. Wittig-Horner coupling of 34a with the protected 25-hydroxy Grundmann's ketone 161 generated the target compound 163 after the deprotection of TBS-protecting groups.

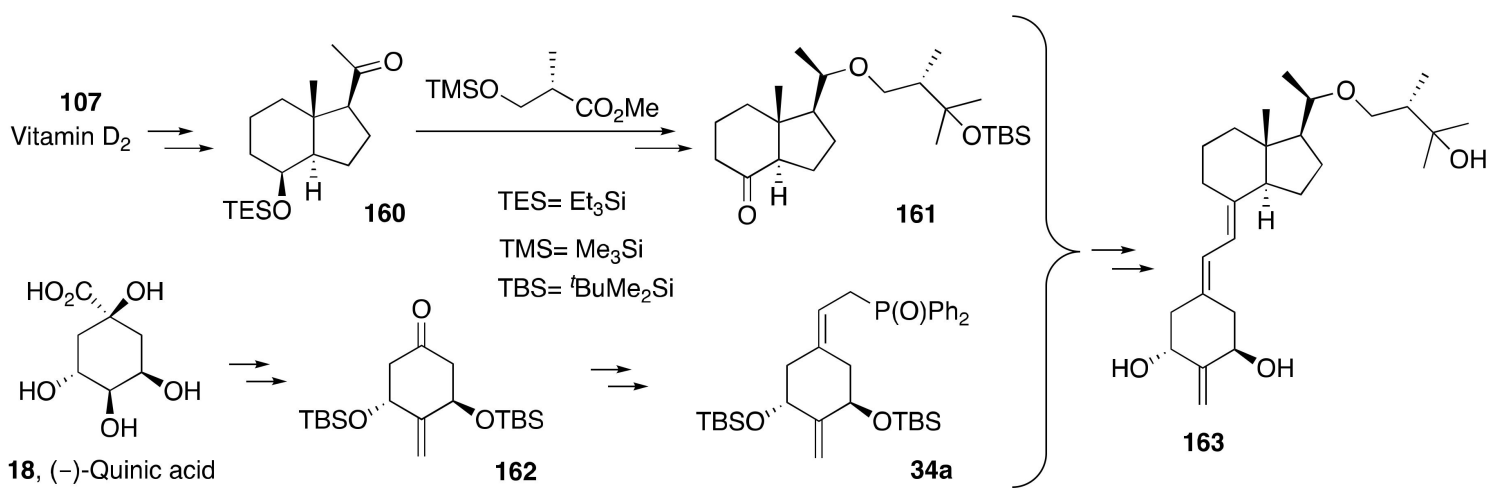

Scheme 31. Synthesis of (20S)-24R-methyl-2-methylene-22-oxa-1 $\alpha, 25$-dihydroxy-19-nor-vitamin $\mathrm{D}_{3}$.

\section{Synthesis of Diene-Modified $1 \alpha, 25-(\mathrm{OH})_{2}-19-$ nor-Vitamin D}

DeLuca's group [62] previously reported the synthesis of a C6-methyl-substituted derivative of $1 \alpha, 25-(\mathrm{OH})_{2}-\mathrm{D}_{3}$. This analog rearranges easily to its previtamin form and binds VDR very effectively. In order to test this modification in the vitamin form, a series of 6-substituted analogs of $1 \alpha$,25-dihydroxy-19-nor-vitamin $\mathrm{D}_{3}$ were prepared, which are unable to undergo a conversion to their respective previtamin forms. The syntheses of analogs 167 (Scheme 32) bearing different substituents at C6 were accomplished by Suzuki-Miyaura cross-coupling reactions of a bicyclic organoboron derivative 29 with the respective alkenyl halides 165 or 166, synthesized from precursor 164.

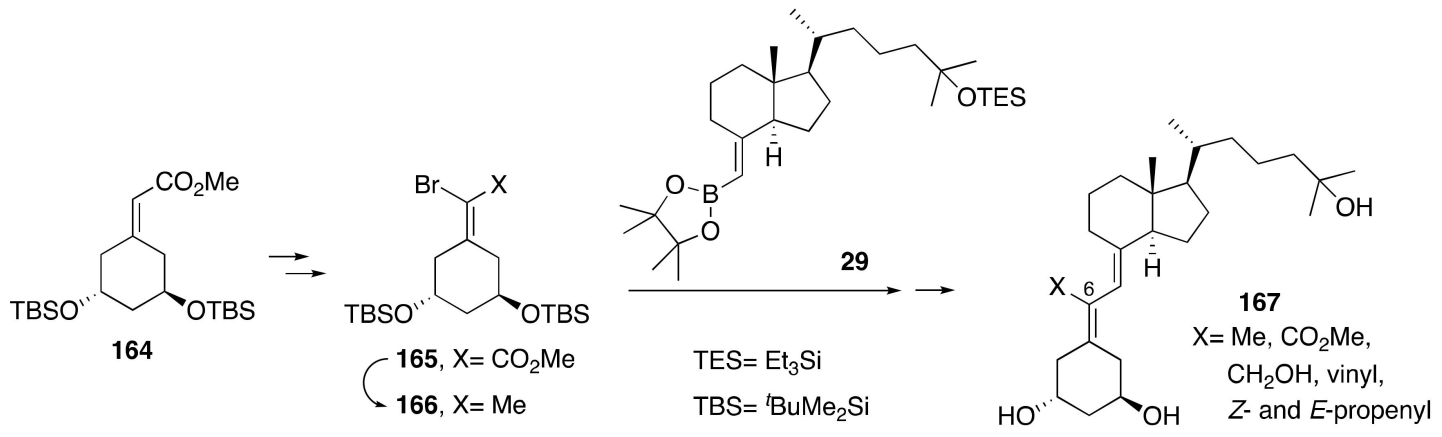

Scheme 32. Synthesis of 6-substituted $1 \alpha, 25$-dihydroxy-19-nor-vitamin $\mathrm{D}_{3}$.

\section{Synthesis of CD-Ring-Modified $1 \alpha, 25-(\mathrm{OH})_{2}-19-$ nor-Vitamin D}

\subsection{Synthesis of C-Ring- and Side-Chain-Modified Analogs}

Vandewalle and co-workers [63] described the synthesis of seco C9,11,21-trisnor-17-methyl$1 \alpha, 25$-dihydroxyvitamin $\mathrm{D}_{3}$ analogs 170 (Scheme 33). These analogs attracted their attention since modifications of that part of vitamin D are the least studied. The structure lacks the six-membered C-ring. To prepare the upper fragment of the molecule, $(1 S, 3 R)$-camphoric acid 168 is a good template. A highly efficient two-step differentiation of the carboxylic functions in $\mathbf{1 6 8}$ was attained via silylation of the corresponding diol, affording an aldehyde precursor 169 after several steps. Finally, construction of the title compounds 170 involved Lythgoe coupling of aldehydes 169 with an A-ring phosphine oxide 23, followed by deprotection of the hydroxy functions. The coupling was performed on D-ring/side chain fragments possessing a free 25-hydroxy function; therefore, an excess of $\mathbf{2 3}$ was used, but the A-ring phosphine oxide could be recuperated. 


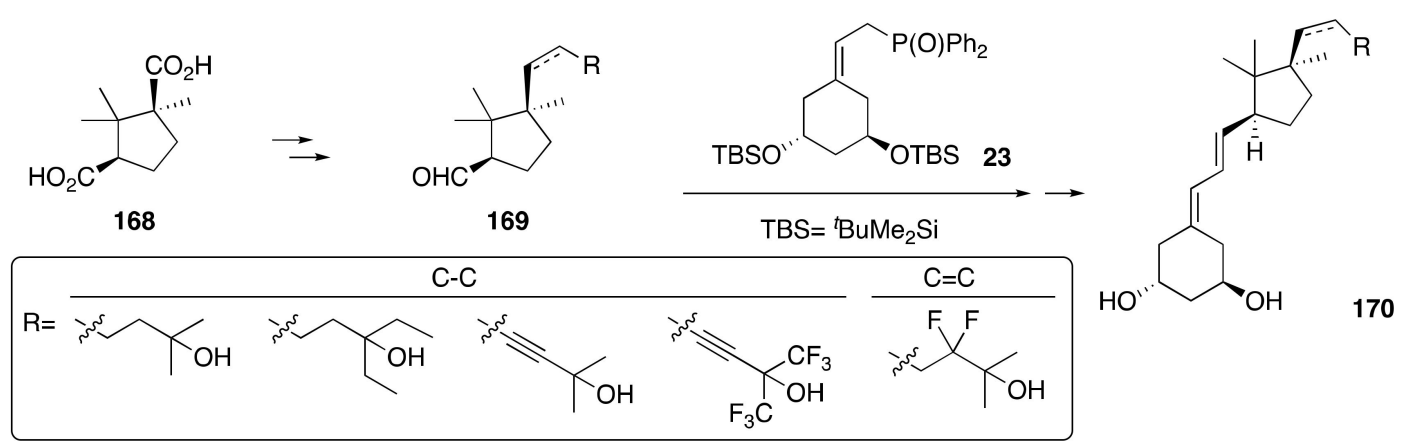

Scheme 33. Synthesis of C-ring- and side-chain-modified $1 \alpha, 25$-dihydroxy-19-nor-vitamin $\mathrm{D}_{3}$.

\subsection{Synthesis of D-Ring- and Side-Chain-Modified Analogs}

Several vitamin D analogs $\mathbf{1 7 3}$ and $\mathbf{1 7 6}$ with natural configurations at C17R and C20R (Scheme 34), which are characterized by the absence of a D-ring and have different side chains, were described by De Clercq's group [64]. Analogs that lack the closed five-membered ring of the CD-ring skeleton were prepared from $(R)-3$-methyl-2-cyclohexen-1-ol (171), which was transformed into the C-ring synthons 172. In addition, using several reactions, the C-ring moiety 175 was obtained from 3-methyl2-cyclohexenone (174). Cyclohexanone derivatives 172 and 175 were each subjected to the usual Wittig-Horner conditions with a phosphine oxide $\mathbf{2 3}$ and, after the removal of the different protecting groups, led to the desired analogs $\mathbf{1 7 3}$ and 176. The same research group [65] also reported the synthesis of four D-ring-modified, natural side chain 19-nor-1 $\alpha, 25-(\mathrm{OH})_{2}-\mathrm{D}_{3}$ derivatives 173 lacking $\mathrm{C} 15$ and diastereomeric at C17 and C20.

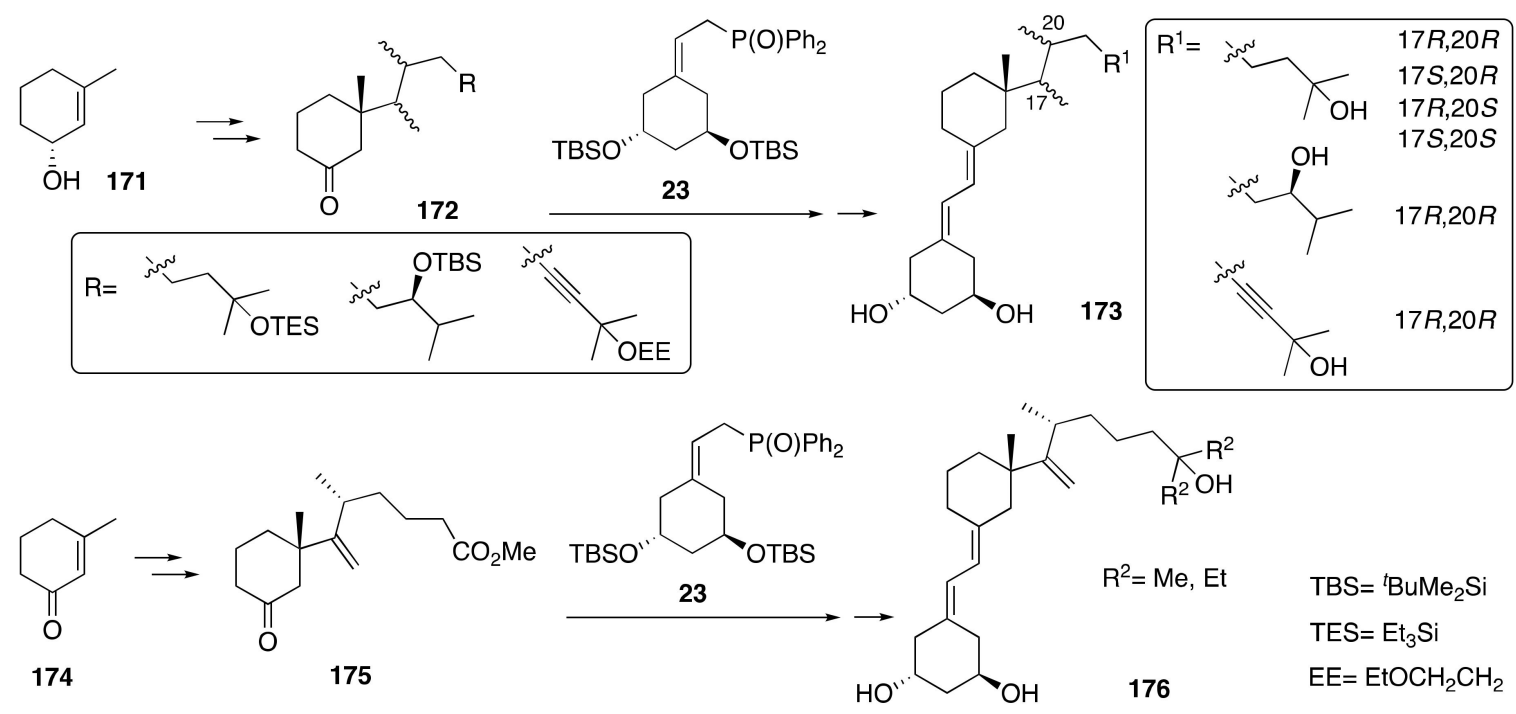

Scheme 34. Synthesis of D-ring- and side-chain-modified $1 \alpha, 25$-dihydroxy-19-nor-vitamin $\mathrm{D}_{3}$.

Vandewalle's group [66,67] presented the synthesis of analogs 179 from a decalin-type CD-ring moiety (Scheme 35). In addition to the fundamental change of the natural hydrindane CD-ring fragment into a decalin system, they also combined this with other modifications as 20-epi and/or 14-epi, the latter being as consequence of the formation of trans- or cis-fused decalin. The starting material was the (S)-Wieland-Miescher ketone 177, which, after removal of the keto function, hydroboration of the double bond, and elaboration of the side chain, led to the synthon 178, ready for coupling. Following that, the Lythgoe coupling of the CD-ring/side chain part $\mathbf{1 7 8}$ and the A-ring synthon precursor 23 gave rise to four different analogs 179. The yields of the coupling of the trans-fused intermediates were lower than that normally observed when the natural hydrindane $C D$ fragment is involved. This could be due to a more severe steric hindrance exerted by the cyclohexane D ring. The reaction of the cis-fused 
decaline precursor produced an even lower yield, again indicating the influence of the nature of the $\mathrm{C} 8$ ketone on the Lythgoe coupling.

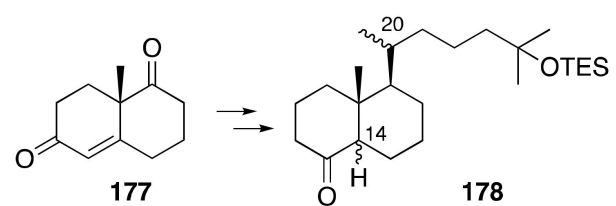

178
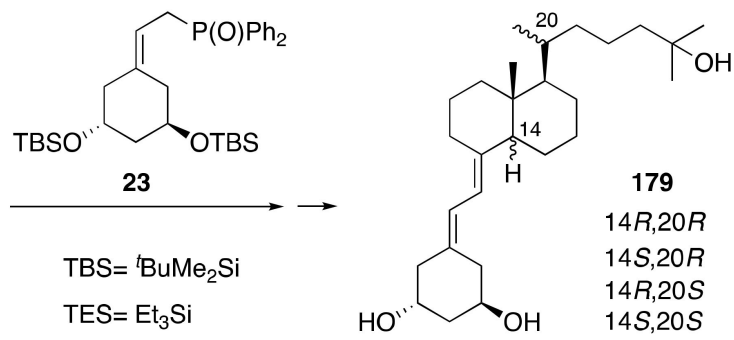

Scheme 35. Synthesis of decalin type CD-ring-and side-chain-modified 1 $\alpha$,25-dihydroxy-19-nor-vitamin $\mathrm{D}_{3}$.

Shimizu's group [68] synthesized eight novel 16-ene-22-thia-26,27-dimethyl-19-nor-vitamin $\mathrm{D}_{3}$ analogs 182 (Scheme 36) bearing side chains of different sizes in combination with 20R- and 20S-isomers. The target compounds were prepared by a convergent Wittig-Horner reaction of an A-ring phosphine oxide 23 with 16-ene-22-thia-25-hydroxy Grundmann's ketones $\mathbf{1 8 1}$ having differently sized side chains, which were derived from a ketone 180, obtained starting from vitamin $\mathrm{D}_{2}$. The biological activities of (20S)-22-thia compounds were more potent than those of the corresponding 20R-counterparts. Furthermore, the binding affinity of the derivatives 182 to VDR suggest that elongation of the side chain in 22-thia analogs by up to one carbon can be stably accommodated in the VDR binding pocket.

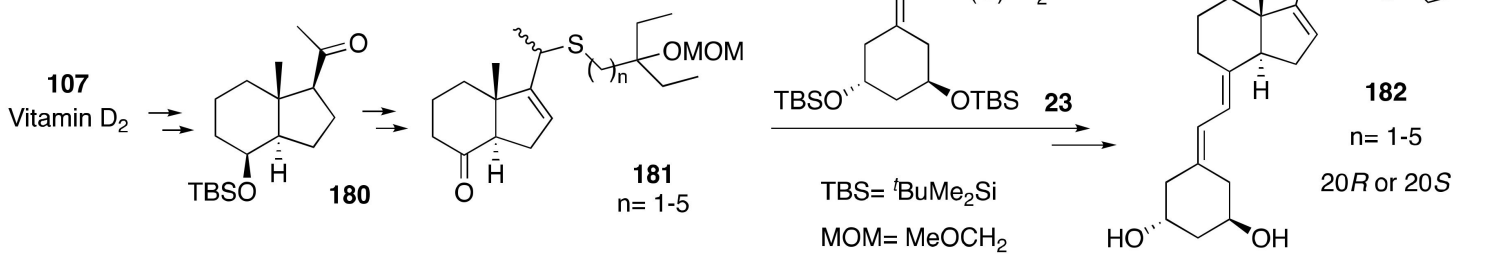

Scheme 36. Synthesis of 16-ene-22-thia-19-nor-vitamin $\mathrm{D}_{3}$ analogs with side chains of different sizes.

\subsection{Synthesis of CD-Ring-Modified Analogs}

DeLuca and co-workers [69] reported an 18,19-dinor analog 184 of $1 \alpha, 25-(\mathrm{OH})_{2}-\mathrm{D}_{3}$ (Scheme 37) to examine the effect of the removal of the $13 \beta$-methyl substituent on biological activities. The titled compound was synthesized via Wittig-Horner coupling of a 25-hydroxy-18-nor Grundmann type ketone 183 with the corresponding A-ring phosphine oxide 23. Since the A-ring synthon is known, the attention was focused on the preparation of the appropriate CD-ring fragment, which was obtained from Grundmann's ketone 82, which was efficiently prepared by ozonolysis of vitamin $\mathrm{D}_{3}(\mathbf{1})$. Configuration at $\mathrm{C} 13$ in the 18-nor Grundmann-type ketone was determined by ${ }^{1} \mathrm{H}$ NMR spectroscopy and molecular mechanics calculations. Additional proof of the assigned trans-C/D-junction was further confirmed by chemical transformations.

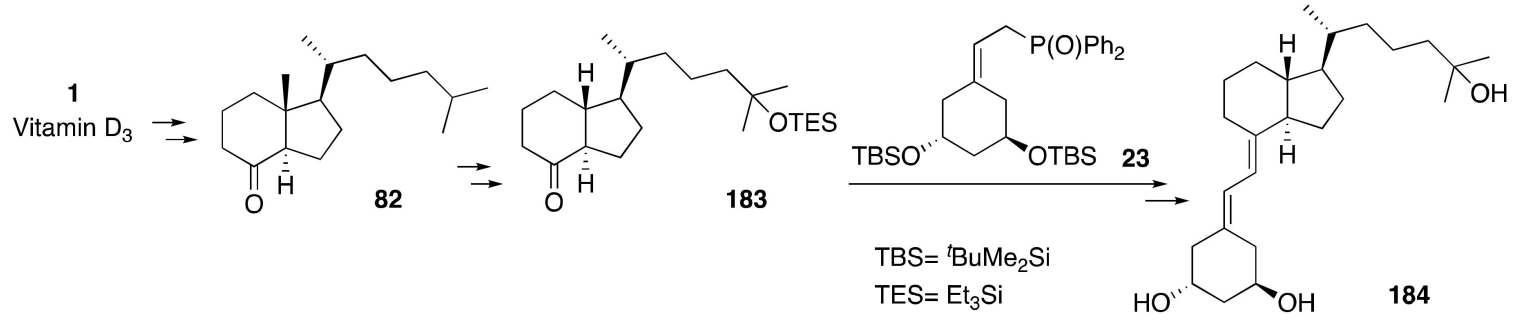

Scheme 37. Synthesis of $1 \alpha, 25$-dihydroxy-18,19-dinor-vitamin $\mathrm{D}_{3}$ analog. 
A convergent route to the A-ring precursors 187 and 188 starting from enantiopure (2S,4S)-1,2,4,5-diepoxypentane (186), which was obtained from 2,4-pentanedione (185), was described by Vandewalle's group (Scheme 38) [70]. Previously, to prepare these A-ring precursors from (-)-quinic acid or from cis-1,3,5-cyclohexanetriol, rather linear approaches were involved. A convergent synthesis of A-ring synthons was investigated since the intermediate 186 serves not only to prepare the bicyclic A-ring 187, but also as a starting point to obtain the phosphine oxide 188. Because of their interest in 14-epi analogs, they synthesized 190 starting from the C/D cis-fused 82. They also developed an alternative route to 190 involving the coupling of an aldehyde 191 with the vinylic lithium derivative obtained from 189a $(\mathrm{R}=\mathrm{Br})$. In addition, they reported [71] a new synthesis for the A-ring precursor 192 from the known 3-cyclopentenol and applied it to the synthesis of $\mathbf{1 9 0}$ upon the reaction of the lithiated intermediate prepared from 192 with the aldehyde $189 \mathrm{~b}(\mathrm{R}=\mathrm{CHO})$.

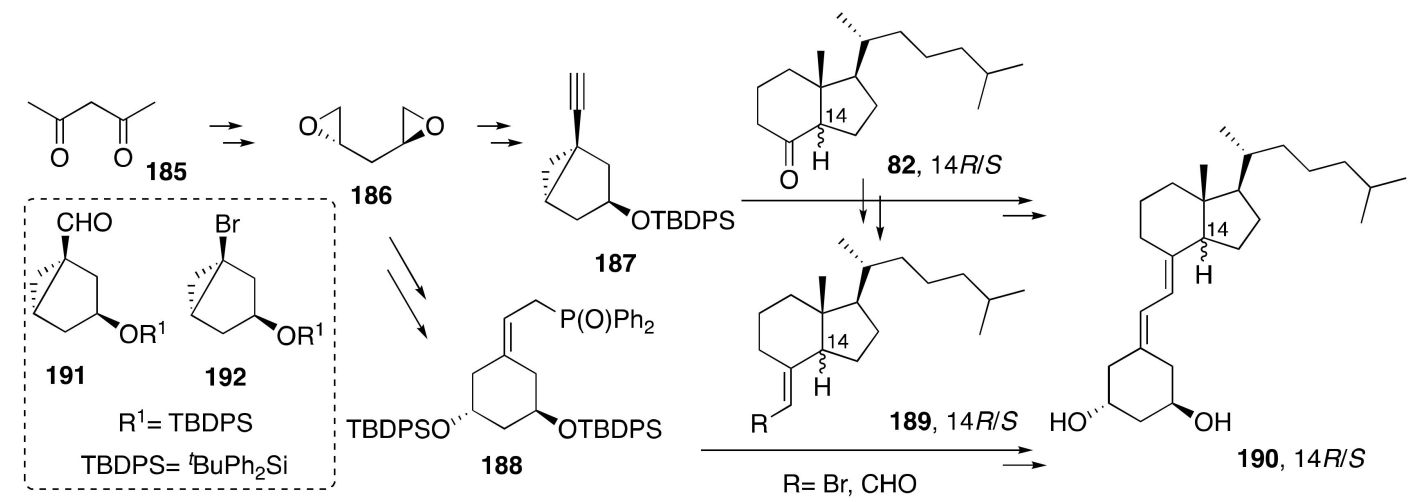

Scheme 38. Synthesis of 14-epi $1 \alpha, 25$-dihydroxy-19-nor-vitamin $\mathrm{D}_{3}$.

\subsection{Synthesis of CD-Ring- and Side-Chain-Modified Analogs}

Vandewalle and co-workers [72] described the synthesis of 14,20-bis-epi-1 $\alpha, 25$-dihydroxy19-nor-vitamin $D_{3}$ and side chain analogs 196 (Scheme 39). The syntheses of CD-ring precursors 195 were performed through the degradation of vitamin $\mathrm{D}_{2}$ via the 14,20-bis-epi-Inhoffen-Lythgoe diol 193 and by total synthesis starting from the Hajos-Wiechert ketone 194. The CD-ring/side chain precursors 195 were coupled with a 19-nor-A-ring precursor 23 using the Wittig-Horner olefination reaction.

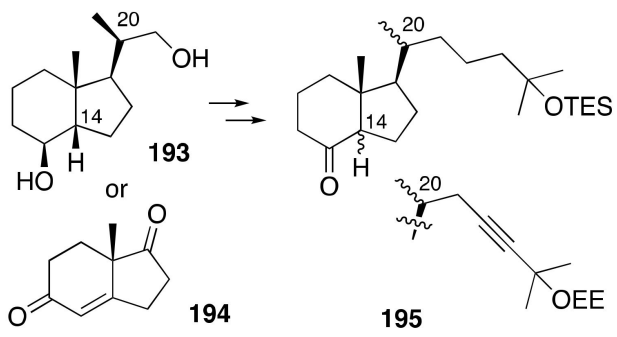

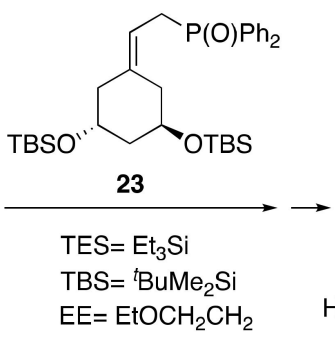

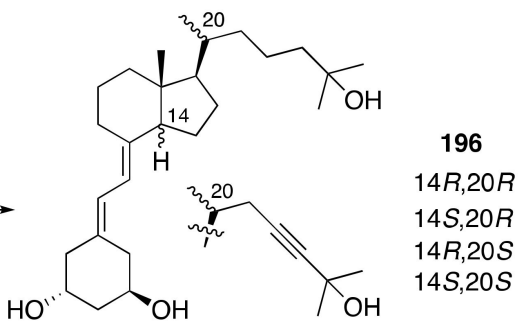

Scheme 39. Synthesis of 14,20-bis-epi 1 $\alpha$,25-dihydroxy-19-nor-vitamin $\mathrm{D}_{3}$.

Retiferol (204, Scheme 40) was selected as a clinical candidate for the evaluation of a potential oral therapy for psoriasis since it is a potent activator of the vitamin $\mathrm{D}$ receptor with low calcemic activity. A short and efficient route to the des-C,D vitamin $D_{3}$ derivative 204 and its enantiomer 205 was described by Hilpert and Wirz [73]. This route features an assembly strategy using a modified Julia olefination of the A-ring ketones 201/202 and the 2-benzothiazolyl sulfone 199. A three-step procedure from the meso trans-1,3,5-cyclohexane triol (200), which involves an enzymatic desymmetrization, was used to prepare the A-ring synthon precursor in the case of analog 204. New routes to the aldehyde 198, prepared from 4-chlorobutanol (197), and to the phosphine oxide 23 and its enantiomer 203 were developed. Alternative coupling strategies (Wittig-Horner or Julia olefinations) were also used. Similarly, the preparation of both enantiomers of the phosphine oxides 23 and 203 was based 
on chemoenzymatic routes starting from meso-1,3,5-trihydroxy cyclohexane derivatives 200 and cis-1,3,5-cyclohexanetriol (19, Scheme 3), respectively. From a variety of assembly strategies evaluated, the uncommon disconnection, accomplished via a modified Julia olefination involving the ketone 201 and the sulfone 199, emerged as the most efficient strategy, resulting in a new short and high-yielding route to the retiferol (204).

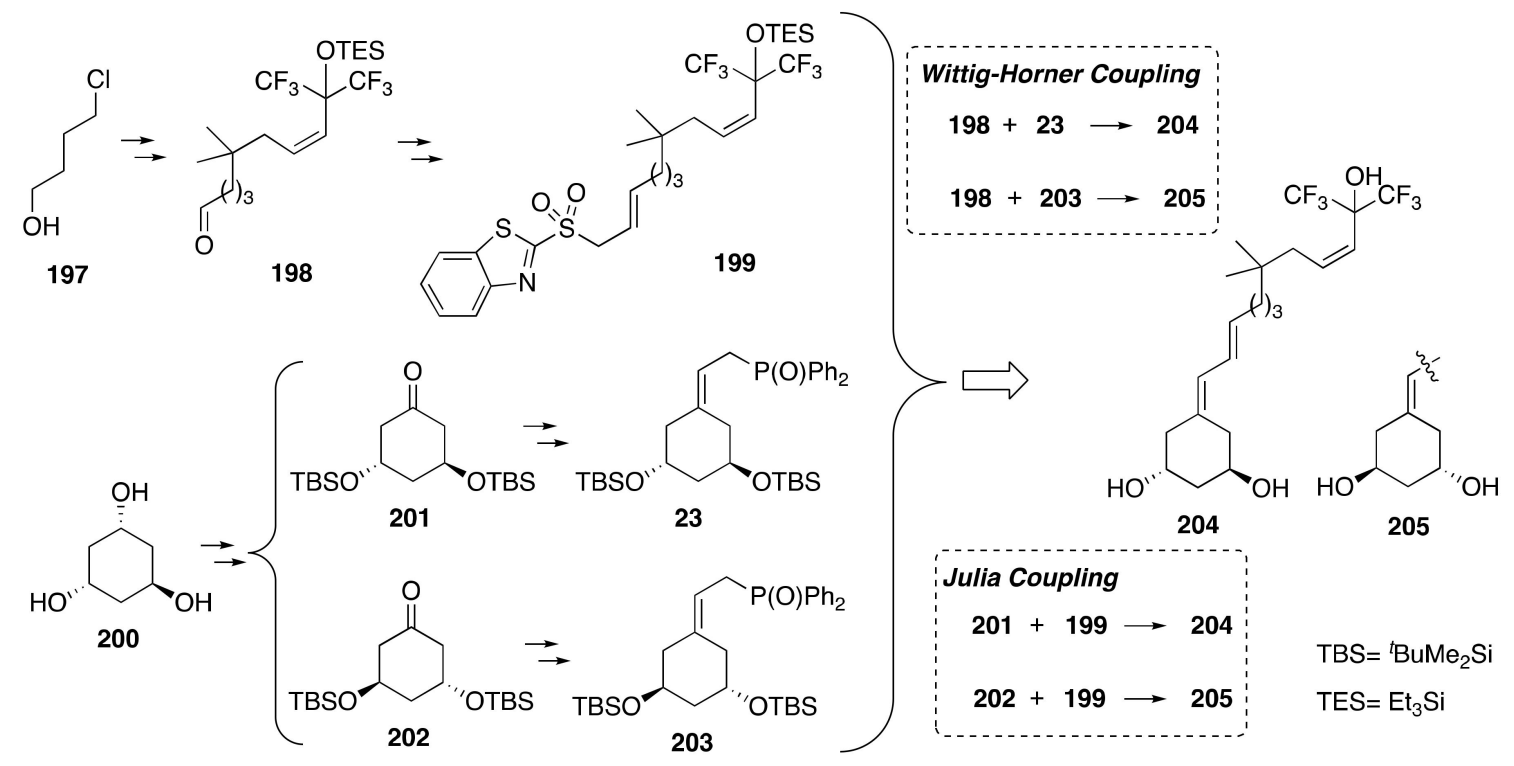

Scheme 40. Synthesis of des-C,D $1 \alpha, 25$-dihydroxy-19-nor-vitamin $\mathrm{D}_{3}$.

Sato and co-workers [74] reported an efficient and high-yield preparation of 207 (Scheme 41) and its utilization for the synthesis of des-C,D derivatives of 19-nor-1 $\alpha, 25$-dihydroxyvitamin $\mathrm{D}_{3}$, including 210 and 213, by the Suzuki-Miyaura coupling. The A-ring intermediate 207, which was efficiently prepared from readily available 5-(tert-butyldimethylsilyl)oxycyclohex-2-enone (206) that came from (S)-epichlorohydrine, reacted with the boronate compound of the C,D-ring portion 209. The latter was prepared by hydroboration of acetylene 208. The method was also applied to a solid-phase synthesis, and the A-ring synthon $\mathbf{2 1 1}$ was easily prepared on a solid support from an intermediate of the synthesis of 207. The coupling of the polymer-bounded A-ring synthon precursor 211 with des-C,D/side chain moieties 212 was the key step to generate the analogs 213 . The solid support synthesis could be applied to the fields of drug discovery and manufacturing.
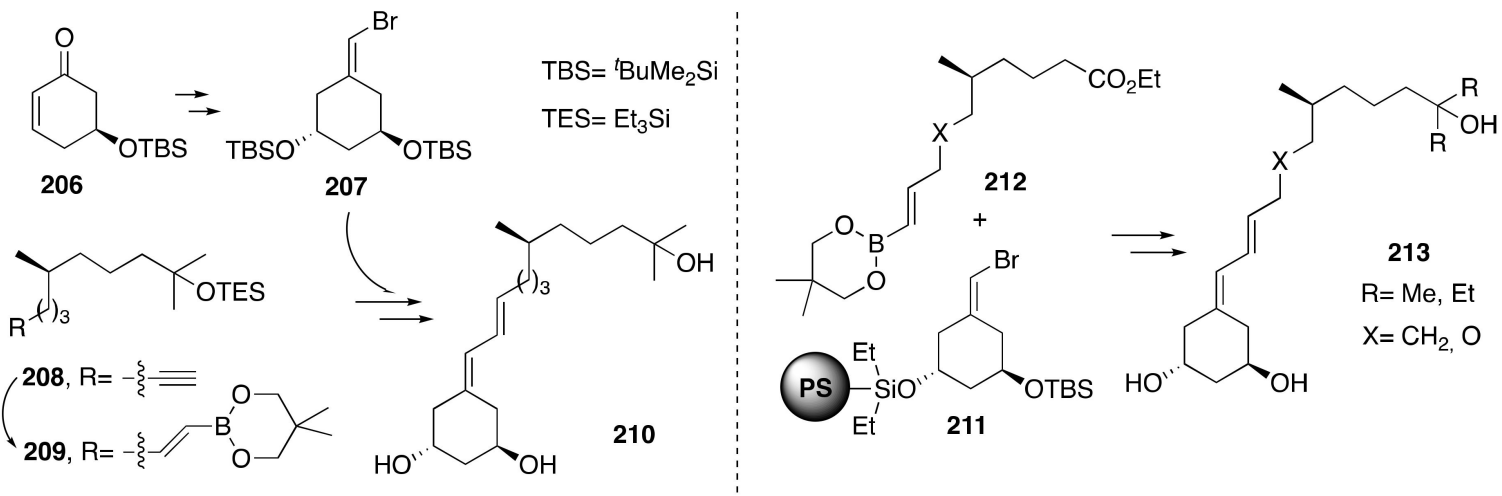

Scheme 41. Synthesis of des-C,D $1 \alpha, 25$-dihydroxy-19-nor-vitamin $\mathrm{D}_{3}$ in solution and on a solid support.

\section{Synthesis of Side-Chain-Modified $1 \alpha, 25-(\mathrm{OH})_{2}-19-n o r-V i t a m i n ~ D$}

With the aim to examine the biological effect of side chain modifications of 19-nor-vitamin $\mathrm{D}$ derivatives, Perlman and DeLuca [75] described a side-chain-homologated 1 $\alpha, 25$-dihydroxy- 
19-nor-vitamin D analog 217 (Scheme 42), which was prepared in a double convergent synthesis with 1 $\alpha$-hydroxy-19-nor-vitamin D C22 aldehyde 215 as a key intermediate. This aldehyde was prepared in a convergent synthesis from the A-ring synthon $\mathbf{2 3}$ obtained from commercially available quinic acid. The readily available Inhoffen-Lythgoe diol served as the basic building block and was obtained from the oxidation of vitamin $\mathrm{D}_{2}(\mathbf{1 0 7})$, providing the $\mathrm{CD}$ ring acetylated moiety 214. Condensation of the A-ring synthon 23 with the ketone 214 in a Wittig-Horner reaction gave the diene 215. Then, this intermediate was used as a precursor to synthesize $\Delta^{22}, 22 E, 19-n o r-24,24-$ dihomo-26,27-dihomo analog 217 via Julia olefination of the 19-nor-22-aldehyde 215 with the corresponding protected phenylsulfone side chain fragment 216.

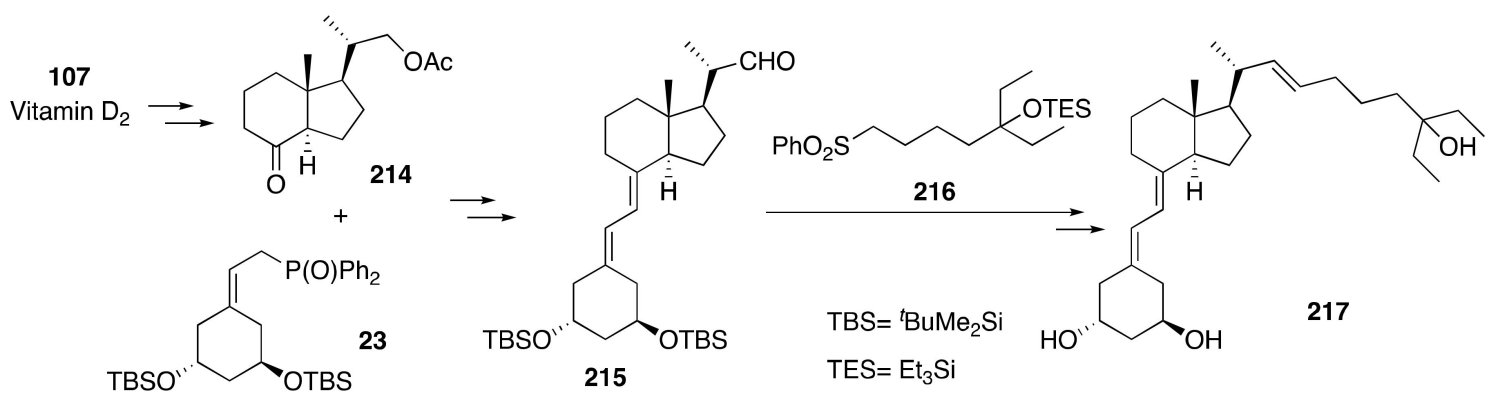

Scheme 42. Synthesis of $\Delta^{22}, 22 E-24,24$-dihomo-26,27-dihomo-1 $\alpha, 25$-dihydroxy-19-nor-vitamin $\mathrm{D}_{3}$.

Mikami, Okano, and co-workers [76] reported the synthesis of a hybrid 22-oxa-1 $\alpha, 25-$ dihydroxy19-nor-vitamin $\mathrm{D}_{3}$ analog 222 (Scheme 43) through Wittig-Horner olefination between the CD-ring/side chain fragment 112 and the A-ring synthon precursor 23. The ene-cyclization substrate $(R)-211$ was prepared via catalytic enantioselective epoxidation of allylic alcohol 220, which was obtained through a regioselective propiolate-ene reaction of homoallylic ether $\mathbf{2 1 8}$ with methyl propiolate (219). Thus, the combination of the regioselective propiolate-ene reaction, catalytic enantioselective epoxidation, and catalytic enantioselective carbonyl-ene cyclization allowed access to the A-ring synthon precursor 23 and the analog 222.

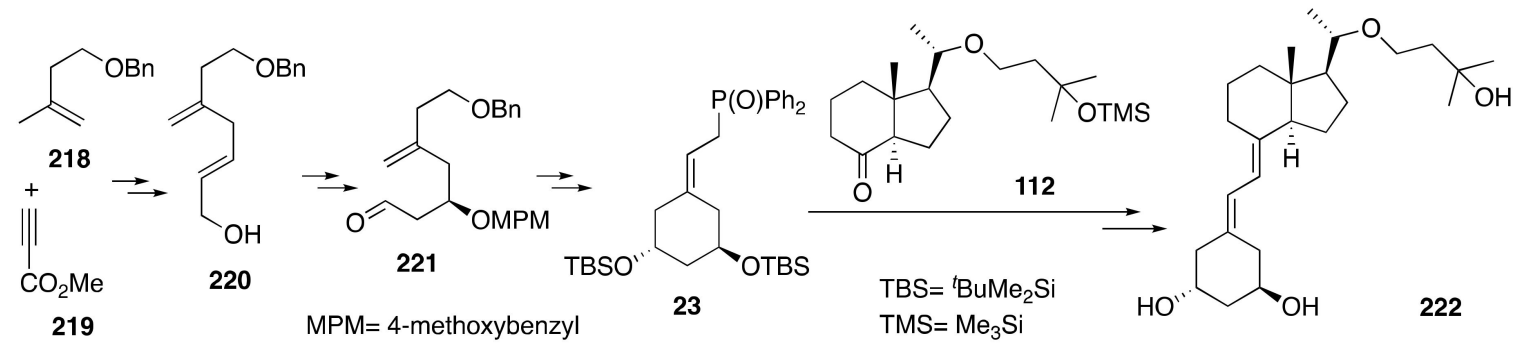

Scheme 43. Synthesis of 22-oxa-1 $\alpha, 25$-dihydroxy-19-nor-vitamin $\mathrm{D}_{3}$ analog.

In a previous report, Reddy's group indicated that $1 \alpha, 23(S), 25$-trihydroxy-24-oxovitamin $\mathrm{D}_{3}$, a natural metabolite of $1 \alpha, 25$-dihydroxyvitamin $\mathrm{D}_{3}$, is almost equipotent to $1 \alpha, 25-(\mathrm{OH})_{2}-\mathrm{D}_{3}$ in suppressing parathyroid hormone $(\mathrm{PTH})$ secretion in addition to possessing only weak in vivo calcemic actions. In an attempt to produce vitamin $\mathrm{D}_{3}$ analogs with a better therapeutic index, Reddy and co-workers [77] synthesized C23 epimers of $1 \alpha, 23,25-(\mathrm{OH})_{3}-24$-oxo-19-nor-vitamin $\mathrm{D}_{3} 224$ (Scheme 44) by coupling the A-ring phosphine oxide 23 with CD-ring ketones 223 using the Horner-Wittig method. The 19-nor A-ring precursor 23 was prepared from quinic acid. The appropriate CD-ring ketones 223 were synthesized from Inhoffen-Lythgoe's diol 117, which was obtained from oxidation of vitamin $\mathrm{D}_{2}$ (107). $1 \alpha, 23(R), 25-(\mathrm{OH})_{3}-24-0 x o-19-n o r-\mathrm{D}_{3} 224 \mathbf{a}$ and, to a lesser extent, its 23(S) diastereomer 224b were potent analogs, and they suppressed PTH secretion in bovine parathyroid cells and strongly inhibited clonal growth and induced differentiation of HL-60 cells in vitro. Using a similar approach, Posner and co-workers [78] reported a new side-chain ketone analog 226 from a diketone 225. Surprisingly, 
the ketone analog 19-nor-226 was not significantly less calcemic in vivo than the corresponding 19-methylene derivative, according to DeLuca's observations that 19-nor analogs are usually much less calcemic than their 19-methylene versions.

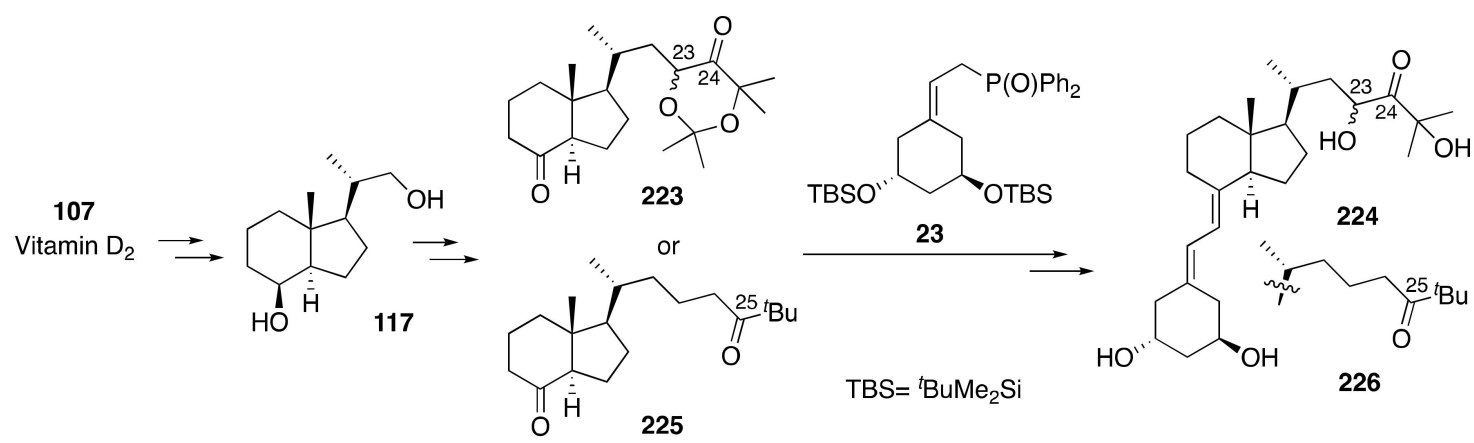

Scheme 44. Synthesis of hydroxy ketones and ketone derivatives of $1 \alpha, 25-(\mathrm{OH})_{2}-19-n o r$-vitamin $\mathrm{D}_{3}$.

Maehr's research group described [79,80] new Gemini analogs 229 (Scheme 45), which consisted of derivatives with two different side chains emanating from C20. The first part of the syntheses involved the preparation of CD-ring synthons and commenced with the previously described Inhoffen-Lythgoe diol, which was transformed into compounds 227. Subsequent reactions led to the ketones 228, which served as suitable coupling partners with the A-ring synthon 23. The second phase of the synthesis included the coupling reactions of the CD-ring moieties 228 with the A-ring precursor 23 using Wittig-Horner conditions. These analogs, featuring 23-yne and 23(E) side-chains, were more active in human breast cancer cell growth inhibition and human leukemia cell differentiation induction than their 23(Z)-counterparts.
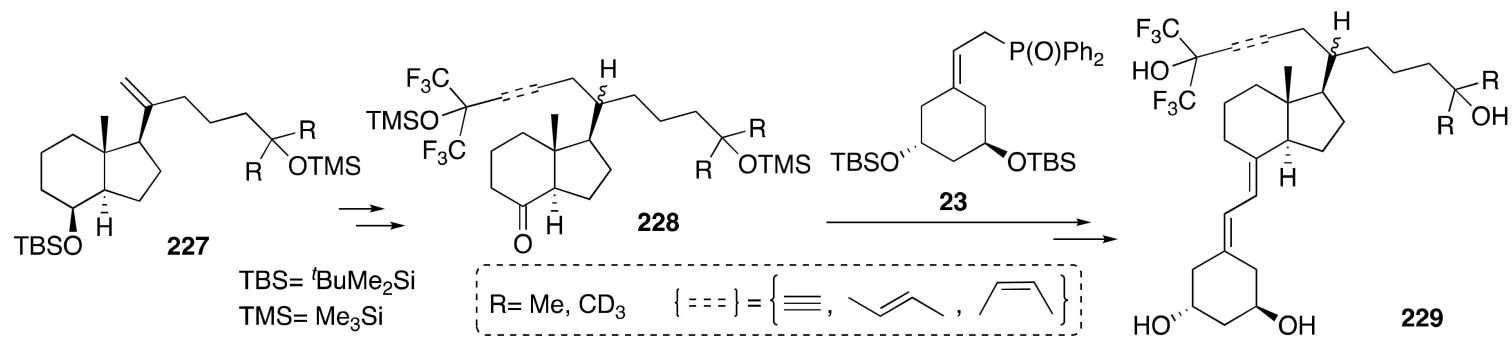

Scheme 45. Synthesis of $1 \alpha, 25$-dihydroxy-19-nor-vitamin $\mathrm{D}_{3}$ Gemini analogs.

The analogs of 19-nor-1,25-(OH) $-\mathrm{D}_{2} 234$ (Scheme 46) with side chain modifications were synthesized by Pietraszek's group [81] using a convergent strategy with the new advanced intermediates 230 and 23. The design of this synthesis was developed while taking into account its possible scale-up for pharmaceutical purposes. Thus, starting from commercially available compounds, vitamin $\mathrm{D}_{2}$ and quinic acid, the synthesis proceeded through convenient bench-stable intermediates. The Wittig-Horner condensation of the phosphine oxide $\mathbf{2 3}$ with the ketone $\mathbf{2 3 0}$ generated the new sulfone $\mathbf{2 3 1}$ as the key intermediate in the synthesis of the title compounds. Julia olefination of the deprotonated sulfone $\mathbf{2 3 1}$ with the aldehydes $\mathbf{2 3 2}$ or $\mathbf{2 3 3}$ gave the corresponding hydroxysulfones. In the first case, the mixture was reacted with a Grignard reagent to give the respective tertiary alcohols, and then radical dehydroxy-desulfonylation followed by desilylation produced the target analogs 234a $(R=M e)$ and $234 b(R=E t)$, respectively. The synthesis of the side chain fragments of paricalcitol 235a and its (24R)-diastereomer 235b started from the homochiral methyl (S)- and (R)-3-hydroxy-2-methylpropionate, respectively. The Grignard reaction of these esters, followed by the Dess-Martin oxidation of the resulting crude diols, yielded the aldehydes 233a and 233b, respectively. 


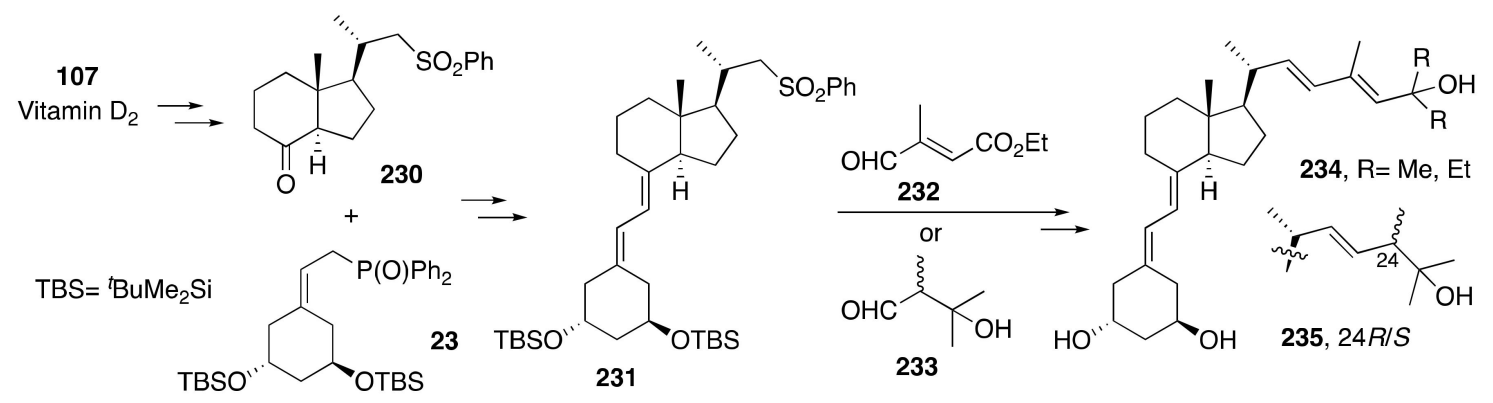

Scheme 46. Synthesis of $1 \alpha, 25$-dihydroxy-19-nor-vitamin $\mathrm{D}_{2}$ analogs.

\section{Concluding Remarks}

Nearly 50 years have passed since the discovery of calcitriol (1 $1 \alpha, 25$-dihydroxyvitamin $\left.\mathrm{D}_{3}\right)$, the hormonally active form of vitamin D. However, the field of vitamin D research continues to progress, and a number of review articles have appeared that describe several aspects of the vitamin $\mathrm{D}$ endocrine system since this hormone modulates numerous physiological functions beyond mineral metabolism. Many hundreds of vitamin D analogs have been synthesized in an attempt to segregate these two opposite effects. A special class of analogs, 19-nor-vitamin D, has been demonstrated to have lower calcemic effects than the natural hormone, maintaining or even increasing the other regulatory activities. As a consequence, a huge effort has been made in relation to the synthesis of new 19-nor-vitamin D derivatives. It is well established that the structural characteristics of the vitamin D analogs play an important role in their mode of action. Therefore, understanding the molecular basis of vitamin D action at the molecular level will be crucial in order to design new analogs. The knowledge accumulated from studies on different derivatives will enable the design of a new generation of vitamin $\mathrm{D}$ analogs with enhanced selectivity. Sometimes, the new derivatives are hybrids, which means that they have more than a single modification in one or more parts within the molecule. The present review provides primary references in the literature that, in the past three decades, have reported the preparation of 19-nor modified vitamin D analogs, which could be interesting to the synthetic chemist as well as to other scientists in related fields who wish to understand the chemical strategies leading to new vitamin $\mathrm{D}$ analogs with useful pharmacological properties of biomedical interest. The details of the behavior of vitamin $\mathrm{D}$ at the molecular level are emerging, but they are still far from complete. It is foreseeable that studies in the near future will continue to develop the design and synthesis of new derivatives. Further research is encouraged in this exciting area, which could yield important therapeutic improvements in the medium-short term.

Author Contributions: The two authors contributed equally. M.F. revised the final version. All authors have read and agreed to the published version of the manuscript.

Funding: Financial support by the Spanish Ministerio de Ciencia e Innovación (MICINN, Project CTQ2014-55015-P) and Principado de Asturias (Project IDI/2018/000181) are gratefully acknowledged.

Conflicts of Interest: The authors declare no conflict of interest.

\section{References}

1. Holick, M.F. Vitamin D deficiency. N. Engl. J. Med. 2007, 357, 266-281. [CrossRef]

2. Dusso, A.S.; Brown, A.J.; Slatopolsky, E. Vitamin D. Am. J. Physiol. Renal Physiol. 2005, 289, F8-F28. [CrossRef] [PubMed]

3. Chen, T.C.; Holick, M.F. Vitamin D and prostate cancer prevention and treatment. Trends Endocrinol. Metab. 2003, 14, 423-430. [CrossRef] [PubMed]

4. Leyssens, C.; Verlinden, L.; Verstuyf, A. Antineoplastic effects of 1,25(OH)2D3 and its analogs in breast, prostate and colorectal cancer. Endocr. Relat. Cancer 2013, 20, R31-R47. [CrossRef]

5. Fernández, S.; Hernández-Martín, A.; González-García, T.; Ferrero, M. Synthesis of 6-s-cis and 6-s-trans A-Ring Modified Vitamin D Analogues. Curr. Top. Med. Chem. 2014, 14, 2424-2445. [CrossRef] [PubMed] 
6. Glebocka, A.; Chiellini, G. A-ring analogs of 1,25-dihydroxyvitamin $\mathrm{D}_{3}$. Arch. Biochem. Biophys. 2012, 523, 48-57. [CrossRef] [PubMed]

7. Agoston, E.S.; Hatcher, M.A.; Kensler, T.W.; Posner, G.H. Vitamin D analogs as anticarcinogenic agents. Anti Cancer Agents Med. Chem. 2006, 6, 53-71. [CrossRef]

8. Saito, N.; Honzawa, S.; Kittaka, A. Recent results on A-ring modification of $1 \alpha, 25$-dihydroxyvitamin $\mathrm{D}_{3}$ : Design and synthesis of VDR-agonists and antagonists with high biological activity. Curr. Top. Med. Chem. 2006, 6, 1273-1288. [CrossRef]

9. Binderup, L.; Binderup, E.; Godtfredsen, W.O.; Kissmeyer, A.M. Development of new vitamin D analogs. In Vitamin D, 2nd ed.; Feldman, D., Pike, J.W., Glorieux., F.H., Eds.; Academic Press: London, UK, 2005; pp. 1489-1510. [CrossRef]

10. Peleg, S.; Posner, G.H. Vitamin D analogs as modulators of vitamin D receptor action. Curr. Topics Med. Chem. 2003, 3, 1555-1572. [CrossRef]

11. Zhu, G.-D.; Okamura, W.H. Synthesis of Vitamin D (Calciferol). Chem. Rev. 1995, 95, 1877-1952. [CrossRef]

12. Lythgoe, B. Synthetic approaches to vitamin D and its relatives. Chem. Soc. Rev. 1980, 9, 449-475. [CrossRef]

13. Perlman, K.L.; Sicinski, R.R.; Schnoes, H.K.; DeLuca, H.F. 1 $\alpha, 25-D i h y d r o x y-19-n o r-v i t a m i n ~ D_{3}$, a novel vitamin D-related compound with potential therapeutic activity. Tetrahedron Lett. 1990, 31, 1823-1824. [CrossRef]

14. Toyoda, A.; Nagai, H.; Yamada, T.; Moriguchi, Y.; Abe, J.; Tsuchida, T.; Nagasawa, K. Novel synthesis of $1 \alpha, 25$-dihydroxy-19-norvitamin D from 25-hydroxyvitamin D. Tetrahedron 2009, 65, 10002-10008. [CrossRef]

15. Huang, P.-Q.; Sabbe, K.; Pottie, M.; Vandewalle, M.; ,P. A novel synthesis of 19-nor $1 \alpha, 25$-Dihydroxyvitamin $\mathrm{D}_{3}$ and related analogues. Tetrahedron Lett. 1995, 36, 8299-8302. [CrossRef]

16. Perlman, K.L.; Swenson, R.E.; Paaren, H.E.; Schnoes, H.K.; DeLuca, H.F. Novel synthesis of 19-nor-vitamin D compounds. Tetrahedron Lett. 1991, 32, 7663-7666. [CrossRef]

17. Nagai, Y.; Tanami, T.; Abe, J.; Nagai, H.; Hamamizu, T.; Kominato, K.; Iida, K.; Nagasawa, K. Synthesis of 19-Nor-Vitamin D A-Ring Synthons via Ring-Closing Olefin Metathesis. Asian J. Org. Chem. 2014, 3, 994-999. [CrossRef]

18. Sicinski, R.R.; Perlman, K.L.; DeLuca, H.F. Synthesis and Biological Activity of 2-Hydroxy and 2-Alkoxy Analogs of $1 \propto, 25$-Dihydroxy-19-norvitaminD 3 . J. Med. Chem. 1994, 37, 3730-3738. [CrossRef]

19. Shimizu, M.; Iwasaki, Y.; Shibamoto, Y.; Sato, M.; DeLuca, H.F.; Yamada, S. Novel Synthesis of 2-Substituted 19-Norvitamin D A-Ring Phosphine Oxide from D-Glucose as a Building Block. Bioorg. Med. Chem. Lett. 2003, 13, 809-812. [CrossRef]

20. Sicinski, R.R.; Prahl, J.M.; Smith, C.M.; DeLuca, H.F. New $1 \propto$,25-Dihydroxy-19-norvitamin $\mathrm{D}_{3}$ Compounds of High Biological Activity: Synthesis and Biological Evaluation of 2-Hydroxymethyl, 2-Methyl, and 2-Methylene Analogues. J. Med. Chem. 1998, 41, 4662-4674. [CrossRef]

21. Sicinski, R.R.; Rotkiewicz, P.; Kolinski, A.; Sicinska, W.; Prahl, J.M.; Smith, C.M.; DeLuca, H.F. 2-Ethyl and 2-Ethylidene Analogues of $1 \alpha, 25$-Dihydroxy-19-norvitamin $\mathrm{D}_{3}$ : Synthesis, Conformational Analysis, Biological Activities, and Docking to the Modeled rVDR Ligand Binding Domain. J. Med. Chem. 2002, 45, 3366-3380. [CrossRef]

22. Glebocka, A.; Sicinski, R.R.; Plum, L.A.; Clagett-Dame, M.; DeLuca, H.F. New 2-Alkylidene $1 \propto$,25-Dihydroxy-19-norvitamin $\mathrm{D}_{3}$ Analogues of High Intestinal Activity: Synthesis and Biological Evaluation of 2-(3'-Alkoxypropylidene) and 2-(3'-Hydroxypropylidene) Derivatives. J. Med. Chem. 2006, 49, 2909-2920. [CrossRef]

23. Ono, K.; Yoshida, A.; Saito, N.; Fujishima, T.; Honzawa, S.; Suhara, Y.; Kishimoto, S.; Sugiura, T.; Waku, K.; Takayama, H.; et al. Efficient Synthesis of 2-Modified $1 \alpha, 25$-Dihydroxy-19-norvitamin $\mathrm{D}_{3}$ with Julia Olefination: High Potency in Induction of Differentiation on HL-60 Cells. J. Org. Chem. 2003, 68, 7407-7415. [CrossRef] [PubMed]

24. Arai, M.A.; Kittaka, A. Novel 2-Alkyl-1 $\alpha, 25$-dihydroxy-19-norvitamin $\mathrm{D}_{3}$ : Efficient Synthesis with Julia Olefination, Evaluation of Biological Activity and Development of New Analyzing System for Co-Activator Recruitment. Anticancer Res. 2006, 26, 2621-2631.

25. Okano, T.; Nakagawa, K.; Kubodera, N.; Ozono, K.; Isaka, A.; Osawa, A.; Terada, M.; Mikami, K. Catalytic asymmetric syntheses and biological activities of singly dehydroxylated 19-nor-1 $\alpha, 25$-dihydroxyvitamin $\mathrm{D}_{3}$ A-ring analogs in cancer cell differentiation and apoptosis. Chem. Biol. 2000, 7, 173-184. [CrossRef] 
26. Arai, M.A.; Tsutsumi, R.; Hara, H.; Chen, T.C.; Sakaki, T.; Urushino, N.; Inouye, K.; Kittaka, A. Synthesis of 25-hydroxy-19-norvitamin $\mathrm{D}_{3}$ analogs and their antiproliferative activities on prostate cells. Heterocycles 2005, 66, 469-479. [CrossRef]

27. Sicinski, R.R.; Glebocka, A.; Plum, L.A.; DeLuca, H.F. Design, Synthesis, and Biological Evaluation of a 1 ,25-Dihydroxy-19-norvitamin $\mathrm{D}_{3}$ Analogue with a Frozen A-Ring Conformation. J. Med. Chem. 2007, 50, 6154-6164. [CrossRef] [PubMed]

28. Glebocka, A.; Sokolowska, K.; Sicinski, R.R.; Plum, L.A.; DeLuca, H.F. New $1 \propto$,25-Dihydroxy-19-norvitamin $\mathrm{D}_{3}$ Compounds Constrained in a Single A-Ring Conformation: Synthesis of the Analogues by Ring-Closing Metathesis Route and Their Biological Evaluation. J. Med. Chem. 2009, 52, 3496-3504. [CrossRef] [PubMed]

29. Glebocka, A.; Sicinski, R.R.; Plum, L.A.; DeLuca, H.F. New $1 \propto, 25$-dihydroxy-19-norvitamin $\mathrm{D}_{3}$ analogs with frozen A-Ring conformation. J. Steroid Biochem. Mol. Biol. 2010, 121, 46-50. [CrossRef] [PubMed]

30. Sánchez-Abella, L.; Fernández, S.; Verstuyf, A.; Verlinden, L.; Gotor, V.; Ferrero, M. Synthesis, Conformational Analysis, and Biological Evaluation of 19-nor-Vitamin $\mathrm{D}_{3}$ Analogues with A-Ring Modifications. J. Med. Chem. 2009, 52, 6158-6162. [CrossRef]

31. Sikervar, V.; Fleet, J.C.; Fuchs, P.L. A general approach to the synthesis of enantiopure 19-nor-Vitamin $D_{3}$ and its C-2 phosphate analogs prepared from cyclohexadienyl sulfone. Chem. Commun. 2012, 48, 9077-9079. [CrossRef]

32. Ibe, K.; Aoki, H.; Takagi, H.; Ken-mochi, K.; Hasegawa, Y.; Hayashi, N.; Okamoto, S. Preparation of 2-hydroxy A-ring precursors for synthesis of vitamin $\mathrm{D}_{3}$ analogues from lyxose. Tetrahedron Lett. 2015, 56, 2315-2318. [CrossRef]

33. González-García, T.; Verstuyf, A.; Verlinden, L.; Fernández, S.; Ferrero, M. Enzymatic Desymmetrization of 19-nor-Vitamin $\mathrm{D}_{3}$ A-Ring Synthon Precursor: Synthesis, Structure Elucidation, and Biological Activity of $1 \alpha, 25$-Dihydroxy-3-epi-19-nor-vitamin $\mathrm{D}_{3}$ and $1 \alpha, 25$-Dihydroxy-19-nor-vitamin $\mathrm{D}_{3}$. Adv. Synth. Catal. 2018, 360, 2762-2772. [CrossRef]

34. Suhara, Y.; Kittaka, A.; Ono, K.; Kurihara, M.; Fujishima, T.; Yoshida, A.; Takayama, H. Design and Efficient Synthesis of New STable $1 \alpha, 25$-Dihydroxy-19-norvitamin $\mathrm{D}_{3}$ Analogues Containing Amide Bond. Bioorg. Med. Chem. Lett. 2002, 12, 3533-3536. [CrossRef]

35. DeBerardinis, A.M.; Madden, D.J.; Banerjee, U.; Sail, V.; Raccuia, D.S.; De Carlo, D.; Lemieux, S.M.; Meares, A.; Hadden, M.K. Structure-Activity Relationships for Vitamin $\mathrm{D}_{3}$-Based Aromatic A-Ring Analogues as Hedgehog Pathway Inhibitors. J. Med. Chem. 2014, 57, 3724-3736. [CrossRef] [PubMed]

36. Shimizu, M.; Miyamoto, Y.; Takaku, H.; Matsuo, M.; Nakabayashi, M.; Masuno, H.; Udagawa, N.; DeLuca, H.F.; Ikura, T.; Ito, N. 2-Substituted-16-ene-22-thia-1 $\alpha, 25$-dihydroxy-26,27-dimethyl-19-norvitamin $\mathrm{D}_{3}$ analogs: Synthesis, biological evaluation, and crystal structure. Bioorg. Med. Chem. Lett. 2008, 16, 6949-6964. [CrossRef]

37. Wu, Y.; Zhao, Y.; Tian, H.; De Clercq, P.; Vandewalle, M.; Berthier, M.; Pellegrino, G.; Maillos, P.; Pascal, J.-C. A Practical Synthesis of 14-epi-19-nor-1 $\alpha, 25$-Dihydroxyvitamin $\mathrm{D}_{3}$ Analogues and Their A-ring Epimers. Eur. J. Org. Chem. 2001, 2001, 3779-3788. [CrossRef]

38. Barycki, R.; Sicinski, R.R.; Plum, L.A.; Grzywacz, P.; Clagett-Dame, M.; DeLuca, H.F. Removal of the 20-methyl group from 2-methylene-19-nor-(20S)-1 $\alpha, 25$-dihydroxyvitamin $\mathrm{D}_{3}$ (2MD) selectively eliminates bone calcium mobilization activity. Bioorg. Med. Chem. 2009, 17, 7658-7669. [CrossRef]

39. Mikami, K.; Koizumi, Y.; Osawa, A.; Terada, M.; Takayama, H.; Nakagawa, K.; Okano, T. BINOL-Ti-Catalyzed Carbonyl-Ene Cyclization by Tuning the 6-Br-Ligand for the Synthesis of 2-Methyl-19-nor-22-oxa Vitamin D Analogue with Significant Differentiation Activity. Synlett 1999, 12, 1899-1902. [CrossRef]

40. Mikami, K.; Ohba, S.; Ohmura, H.; Kubodera, N.; Nakagawa, K.; Okano, T. Asymmetric Catalytic Ene-Cyclization Approach to 2-Fluoro-19-Nor-1,25-Dihydroxyvitamin $\mathrm{D}_{3}$ A-Ring Analog with Significant Transactivation Activity. Chirality 2001, 13, 366-371. [CrossRef]

41. Nakagawa, K.; Okano, T.; Ozono, K.; Kato, S.; Kubodera, N.; Ohba, S.; Itoh, Y.; Mikami, K. Catalytic asymmetric synthesis and anticancer effects of the novel non-calcemic analog of vitamin D, $2 \alpha$-fluoro-19-nor-22-oxa-1 $\alpha$,25-dihydroxyvitamin $\mathrm{D}_{3}$ in metastatic lung carcinoma. J. Fluorine Chem. 2007, 128, 654-667. [CrossRef]

42. Sicinski, R.R.; Prah, J.M.; Smith, C.M.; DeLuca, H.F. New highly calcemic $1 \alpha, 25$-dihydroxy-19-norvitamin $\mathrm{D}_{3}$ compounds with modified side chain: 26,27-dihomo- and 26,27-dimethylene analogs in 20S-series. Steroids 2002, 67, 247-256. [CrossRef] 
43. Plum, L.A.; Prahl, J.M.; Ma, X.; Sicinski, R.R.; Gowlugari, S.; Clagett-Dame, M.; DeLuca, H.F. Biologically active noncalcemic analogs of $1 \alpha, 25$-dihydroxyvitamin $\mathrm{D}$ with an abbreviated side chain containing no hydroxyl. Proc. Natl. Acad. Sci. USA 2004, 101, 6900-6904. [CrossRef] [PubMed]

44. Grzywacz, P.; Plum, L.A.; Sicinski, R.R.; Clagett-Dame, M.; DeLuca, H.F. Methyl substitution of the 25-hydroxy group on 2-methylene-19-nor-1 $\alpha, 25$-dihydroxyvitamin $\mathrm{D}_{3}$ (2MD) reduces potency but allows bone selectivity. Arch. Biochem. Biophys. 2007, 460, 274-284. [CrossRef] [PubMed]

45. Glebocka, A.; Sicinski, R.R.; Plum, L.A.; DeLuca, H.F. Synthesis and Biological Activity of 2-(3'-Hydroxypropylidene)-1 $\alpha$-hydroxy-19-norvitamin D Analogues with Shortened Alkyl Side Chains. J. Med. Chem. 2011, 54, 6832-6842. [CrossRef]

46. Shimizu, M.; Miyamoto, Y.; Kobayashi, E.; Shimazaki, M.; Yamamoto, K.; Reischl, W.; Yamada, S. Synthesis and biological activities of new $1 \alpha, 25$-dihydroxy-19-norvitamin $\mathrm{D}_{3}$ analogs with modifications in both the A-ring and the side chain. Bioorg. Med. Chem. 2006, 14, 4277-4294. [CrossRef]

47. Shimazaki, M.; Miyamoto, Y.; Yamamoto, K.; Yamada, S.; Takami, M.; Shinki, T.; Udagawa, N.; Shimizu, M. Analogs of $1 \alpha, 25$-dihydroxyvitamin $\mathrm{D}_{3}$ with high potency in induction of osteoclastogenesis and prevention of dendritic cell differentiation: Synthesis and biological evaluation of 2-substituted 19-norvitamin D analogs. Bioorg. Med. Chem. 2006, 14, 4645-4656. [CrossRef]

48. Kobayashi, E.; Shimazaki, M.; Miyamoto, Y.; Masuno, H.; Yamamoto, K.; DeLuca, H.F.; Yamada, S.; Shimizu, M. Structure-activity relationships of 19-norvitamin D analogs having a fluoroethylidene group at the C-2 position. Bioorg. Med. Chem. 2007, 15, 1475-1482. [CrossRef]

49. Hatcher, M.A.; Peleg, S.; Dolan, P.; Kensler, T.W.; Sarjeanta, A.; Posner, G.H. A-ring hydroxymethyl 19-nor analogs of the natural hormone $1 \alpha, 25$-dihydroxyvitamin $\mathrm{D}_{3}$ : Synthesis and preliminary biological evaluation. Bioorg. Med. Chem. 2005, 13, 3964-3976. [CrossRef]

50. Shimizu, M.; Iwasaki, Y.; Shimazaki, M.; Amano, Y.; Yamamoto, K.; Reischl, W.; Yamada, S. New derivatives of $1 \alpha, 25$-dihydroxy-19-norvitamin $\mathrm{D}_{3}$ with two substituents at C-2: Synthesis and biological activity. Bioorg. Med. Chem. Lett. 2005, 15, 1451-1455. [CrossRef]

51. Igarashi, M.; Yoshimoto, N.; Yamamoto, K.; Shimizu, M.; Ishizawa, M.; Makishima, M.; DeLuca, H.F.; Yamada, S. Identification of a highly potent vitamin D receptor antagonist: (25S)-26-Adamantyl-25-hydroxy-2methylene-22,23-didehydro-19,27-dinor-20-epi-vitamin D (ADMI3). Arch. Biochem. Biophys. 2007, 460, 240-253. [CrossRef]

52. Nakabayashi, M.; Yamada, S.; Yoshimoto, N.; Tanaka, T.; Igarashi, M.; Ikura, T.; Ito, N.; Makishima, M.; Tokiwa, H.; DeLuca, H.F.; et al. Crystal Structures of Rat Vitamin D Receptor Bound to Adamantyl Vitamin D Analogs: Structural Basis for Vitamin D Receptor Antagonism and Partial Agonism. J. Med. Chem. 2008, 51, 5320-5329. [CrossRef] [PubMed]

53. Yoshimoto, N.; Inaba, Y.; Yamada, S.; Makishima, M.; Shimizu, M.; Yamamoto, K. 2-Methylene 19-nor-25-dehydro-1 $\alpha$-hydroxyvitamin $\mathrm{D}_{3}$ 26,23-lactones: Synthesis, biological activities and molecular basis of passive antagonism. Bioorg. Med. Chem. 2008, 16, 457-473. [CrossRef] [PubMed]

54. Chiellini, G.; Grzywacz, P.; Plum, L.A.; Barycki, R.; Clagett-Dame, M.; DeLuca, H.F. Synthesis and biological properties of 2-methylene-19-nor-25-dehydro-1 $\alpha$-hydroxyvitamin $\mathrm{D}_{3}$-26,23-lactones-Weak agonists. Bioorg. Med. Chem. 2008, 16, 8563-8573. [CrossRef]

55. Sakamaki, Y.; Inaba, Y.; Yoshimoto, N.; Yamamoto, K. Potent Antagonist for the Vitamin D Receptor: Vitamin D Analogues with Simple Side Chain Structure. J. Med. Chem. 2010, 53, 5813-5826. [CrossRef] [PubMed]

56. Yoshimoto, N.; Sakamaki, Y.; Haeta, M.; Kato, A.; Inaba, Y.; Itoh, T.; Nakabayashi, M.; Ito, N.; Yamamoto, K. Butyl Pocket Formation in the Vitamin D Receptor Strongly Affects the Agonistic or Antagonistic Behavior of Ligands. J. Med. Chem. 2012, 55, 4373-4381. [CrossRef] [PubMed]

57. Flores, A.; Sicinski, R.R.; Grzywacz, P.; Thoden, J.B.; Plum, L.A.; Clagett-Dame, M.; DeLuca, H.F. A 20 S Combined with a $22 R$ Configuration Markedly Increases both in Vivo and in Vitro Biological Activity of 1 $\alpha$,25-Dihydroxy-22-methyl-2-methylene-19-norvitamin $\mathrm{D}_{3}$. J. Med. Chem. 2012, 55, 4352-4366. [CrossRef]

58. Grzywacz, P.; Chiellini, G.; Plum, L.A.; Clagett-Dame, M.; DeLuca, H.F. Removal of the 26-Methyl Group from 19-nor-1 $\alpha, 25$-Dihydroxyvitamin $\mathrm{D}_{3}$ Markedly Reduces in Vivo Calcemic Activity without Altering in Vitro VDR Binding, HL-60 Cell Differentiation, and Transcription. J. Med. Chem. 2010, 53, 8642-8649. [CrossRef] 
59. Grzywacz, P.; Plum, L.A.; Clagett-Dame, M.; DeLuca, H.F. 26- and 27-Methyl groups of 2-substituted, 19-nor-1 $\alpha, 25$-dihydroxylated vitamin $\mathrm{D}$ compounds are essential for calcium mobilization in vivo. Bioorg. Chem. 2013, 47, 9-16. [CrossRef] [PubMed]

60. Sibilska, I.; Barycka, K.M.; Sicinski, R.R.; Plum, L.A.; DeLuca, H.F. 1-Desoxy analog of 2MD: Synthesis and biological activity of (20S)-25-hydroxy-2-methylene-19-norvitamin $\mathrm{D}_{3}$. J. Steroid Biochem. Mol. Biol. 2010, 121, 51-55. [CrossRef]

61. Chen, B.; Kawai, M.; Wu-Wong, J.R. Synthesis of VS-105: A novel and potent vitamin D receptor agonist with reduced hypercalcemic effects. Bioorg. Med. Chem. Lett. 2013, 23, 5949-5952. [CrossRef]

62. Sokolowska, K.; Sicinski, R.R.; Mouriño, A.; Plum, L.A.; DeLuca, H.F. Synthesis and biological evaluation of novel 6-substituted analogs of $1 \propto$,25-dihydroxy-19-norvitamin $\mathrm{D}_{3}$. J. Steroid Biochem. Mol. Biol. 2013, 136, 30-33. [CrossRef] [PubMed]

63. Wu, Y.; Sabbe, K.; De Clercq, P.; Vandewalle, M.; Bouillon, R.; Verstuyf, A. Vitamin $\mathrm{D}_{3}$ : Synthesis of seco C-9,11,21-trisnor-17-Methyl-1 $\alpha, 25-$ dihydroxyvitamin $\mathrm{D}_{3}$ Analogues. Bioorg. Med. Chem. Lett. 2002, 12, 1629-1632. [CrossRef]

64. Zhu, G.-D.; Chen, Y.; Zhou, X.; Vandewalle, M.; De Clercq, P.J. Synthesis of CD-ring modified $1 \alpha, 25-$ dihydroxy Vitamin D Analogues: C-ring Analogues. Bioorg. Med. Chem. Lett. 1996, 6, 1703-1708. [CrossRef]

65. Zhou, X.; Zhu, G.-D.; Van Haver, D.; Vandewalle, M.; De Clercq, P.J.; Verstuyf, A.; Bouillon, R. Synthesis,

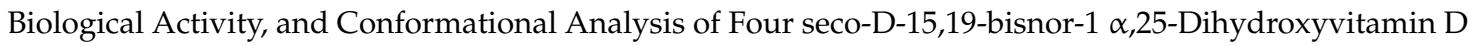
Analogues, Diastereomeric at C17 and C20. J. Med. Chem. 1999, 42, 3539-3556. [CrossRef] [PubMed]

66. Chen, Y.-J.; De Clercq, P.; Vandewalle, M. Synthesis of New Vitamin $\mathrm{D}_{3}$ Analogues with a Decalin-type CD-Ring. Tetrahedron Lett. 1996, 37, 9361-9364. [CrossRef]

67. Chen, Y.-J.; Gao, L.-J.; Murad, I.; Verstuyf, A.; Verlinden, L.; Verboven, C.; Bouillon, R.; Viterbo, D.; Milanesio, M.; Van Haver, D.; et al. Synthesis, biological activity, and conformational analysis of CD-ring modified trans-decalin $1 \alpha$,25-dihydroxyvitamin D analogs. Org. Biomol. Chem. 2003, 1, 257-267. [CrossRef]

68. Takaku, H.; Miyamoto, Y.; Asami, S.; Shimazaki, M.; Yamada, S.; Yamamoto, K.; Udagawa, N.; DeLuca, H.F.; Shimizu, M. Synthesis and structure-activity relationships of 16-ene-22-thia-1 $\alpha, 25$-dihydroxy-26, 27-dimethyl-19-norvitamin $\mathrm{D}_{3}$ analogs having side chains of different sizes. Bioorg. Med. Chem. 2008, 16, 1796-1815. [CrossRef]

69. Sicinski, R.R.; Perlman, K.L.; Prahl, J.; Smith, C.; DeLuca, H.F. Synthesis and Biological Activity of 1 ג,25-Dihydroxy-18-norvitamin $\mathrm{D}_{3}$ and 1 ,25-Dihydroxy-18,19-dinorvitamin $\mathrm{D}_{3}$. J. Med. Chem. 1996, 39, 4497-4506. [CrossRef]

70. Zhou, S.-Z.; Anne, S.; Vandewalle, M. A Practical Synthesis of A-ring Precursors for 19-Nor-1 $\alpha, 25$-dihydroxyvitamin $\mathrm{D}_{3}$ Analogues. Tetrahedron Lett. 1996, 37, 7637-7640. [CrossRef]

71. Yong, W.; Vandewalle, M. A New A-ring Precursor for 19-Nor-1 $\alpha, 25$-dihydroxyvitamin $\mathrm{D}_{3}$ Analogues. Synlett 1996, 9, 911-912. [CrossRef]

72. Van Gool, M.; Zhao, X.; Sabbe, K.; Vandewalle, M. Synthesis of 14,20-Bis-epi-1 $\alpha, 25$-dihydroxy-19-norvitamin $\mathrm{D}_{3}$ and Analogues. Eur. J. Org. Chem. 1999, 1999, 2241-2248. [CrossRef]

73. Hilpert, H.; Wirz, B. Novel versatile approach to an enantiopure 19-nor, des-C,D vitamin $\mathrm{D}_{3}$ derivative. Tetrahedron 2001, 57, 681-694. [CrossRef]

74. Hanazawa, T.; Wada, T.; Masuda, T.; Okamoto, S.; Sato, F. Novel Synthetic Approach to 19-nor-1 $\alpha, 25$-Dihydroxyvitamin $\mathrm{D}_{3}$ and Its Derivatives by Suzuki-Miyaura Coupling in Solution and on Solid Support. Org. Lett. 2001, 3, 3975-3977. [CrossRef] [PubMed]

75. Perlman, K.L.; DeLuca, H.F. $1 \alpha$-Hydroxy-19-Nor-Vitamin D C-22 Aldehyde. A Valuable Intermediate in the Synthesis of Side Chain Modified 1 \&,25-Dihydroxy-19-Nor-Vitamin D3. Tetrahedron Lett. 1992, 33, 2937-2940. [CrossRef]

76. Mikami, K.; Osawa, A.; Isaka, A.; Sawa, E.; Shimizu, M.; Terada, M.; Kubodera, N.; Nakagawa, K.; Tsugawa, N.; Okano, T. "Symmetry" in the Synthesis of the A-Ring of a Vitamin D Hybrid Analogue with Significant Transactivation Activity: A Combinatorial Sequence of Regioselective Propiolate-Ene, Catalytic Enantioselective Epoxidation and Carbonyl-Ene Cyclization Reactions. Tetrahedron Lett. 1998, 39, 3359-3362. [CrossRef] 
77. Lee, N.E.; Williard, P.G.; Brown, A.J.; Campbell, M.J.; Koeffler, H.P.; Peleg, S.; Rao, D.S.; Reddy, G.S. Synthesis and biological activities of the two $\mathrm{C}(23)$ epimers of $1 \alpha, 23,25$-trihydroxy-24-oxo-19-nor-vitamin $\mathrm{D}_{3}$ : Novel analogs of $1 \alpha, 23(S), 25$-trihydroxy-24-oxo-vitamin $\mathrm{D}_{3}$, a natural metabolite of $1 \alpha, 25$-dihydroxyvitamin $\mathrm{D}_{3}$. Steroids 2000, 65, 252-265. [CrossRef]

78. Posner, G.H.; Kim, H.J.; Kahraman, M.; Jeon, H.B.; Suh, B.C.; Li, H.; Dolan, P.; Kensler, T.W. Highly antiproliferative, low-calcemic, side-chain ketone analogs of the hormone $1 \alpha, 25$-dihydroxyvitamin $\mathrm{D}_{3}$. Bioorg. Med. Chem. 2005, 13, 5569-5580. [CrossRef]

79. Maehr, H.; Uskokovic, M.R. Formal Desymmetrization of the Diastereotopic Chains in Gemini Calcitriol Derivatives with Two Different Side Chains at C-20. Eur. J. Org. Chem. 2004, 2004, 1703-1713. [CrossRef]

80. Maehr, H.; Lee, H.J.; Perry, B.; Suh, N.; Uskokovic, M.R. Calcitriol Derivatives with Two Different Side Chains at C-20. V. Potent Inhibitors of Mammary Carcinogenesis and Inducers of Leukemia Differentiation. J. Med. Chem. 2009, 52, 5505-5519. [CrossRef]

81. Pietraszek, A.; Malinska, M.; Chodynski, M.; Krupa, M.; Krajewski, K.; Cmoch, P.; Wozniak, K.; Kutner, A. Synthesis and crystallographic study of 1,25-dihydroxyergocalciferol analogs. Steroids 2013, 78, 1003-1014. [CrossRef]

(C) 2020 by the authors. Licensee MDPI, Basel, Switzerland. This article is an open access article distributed under the terms and conditions of the Creative Commons Attribution (CC BY) license (http://creativecommons.org/licenses/by/4.0/). 